\title{
Anomalous terrain at Dove Crags 'cirqueform' and Gasgale Gill asymmetric valley, English Lake District, attributed to large-scale RSF of pre-LGM origins
}

\section{David Jarman and Peter Wilson}

\section{Supporting Information ppt}

SI-02 - 04 Lake District RSF distribution, site locations; Northwestern Fells locus; Dove Crags RSF causes*

SI-05 - 09 Gasgale Gill valley

SI-10 - 21 Dove Crags cirque and slipmass; moraines

SI-22 - 24 Hause Crag scar and slipmass

SI-25 - 30 Liza Beck cutbank sections, springs, dry channels

SI-31 - 35 reconstruction - pre-RSF Gasgale valley, Grasmoor plateau, Whiteside ridge

SI-36 - 39 the vicinity - Coledale Hause; Hope Gill; cirque pattern and seeding*

SI-40 - 45 comparator sites (Lake District) : Clough Head / Cotley / Robinson / Revelin Crag / Fairfield / Kirk Fell / Whelter Crags

$\mathrm{SI}-46$

SI-47 - 50

(Snowdonia) : Pen yr Helgi-du

SI-51 - 52

(Highlands / Sweden) : Cobbler / Streap, Karkevagge / Sgurr an Fhuarail / Tullich Hill

SI-53 - 54

SI-55 - 58

SI-59- 60

SI-61 - 62

SI-63

alternative interpretations - cirque floor rebound* (B an Fhidhleir); parafluvial RSF* (B Buidhe Arnisdale)

general diagrams - RSF typology; Lakes RSF:geology; non-exploitation of RSF cavities by glaciers

- measures of RSF depth; cataclinal slopes; zone of crush : Beinn Fhada; Norway drill logs

Gasgale Gill diagrams - volume calculations - long sections

- sequence of events : spatial / temporal

comparator reconstruction - Clough Head

* text slides - additional discussion material 
- $0.25-1.00$

- $1.00+$

- possible
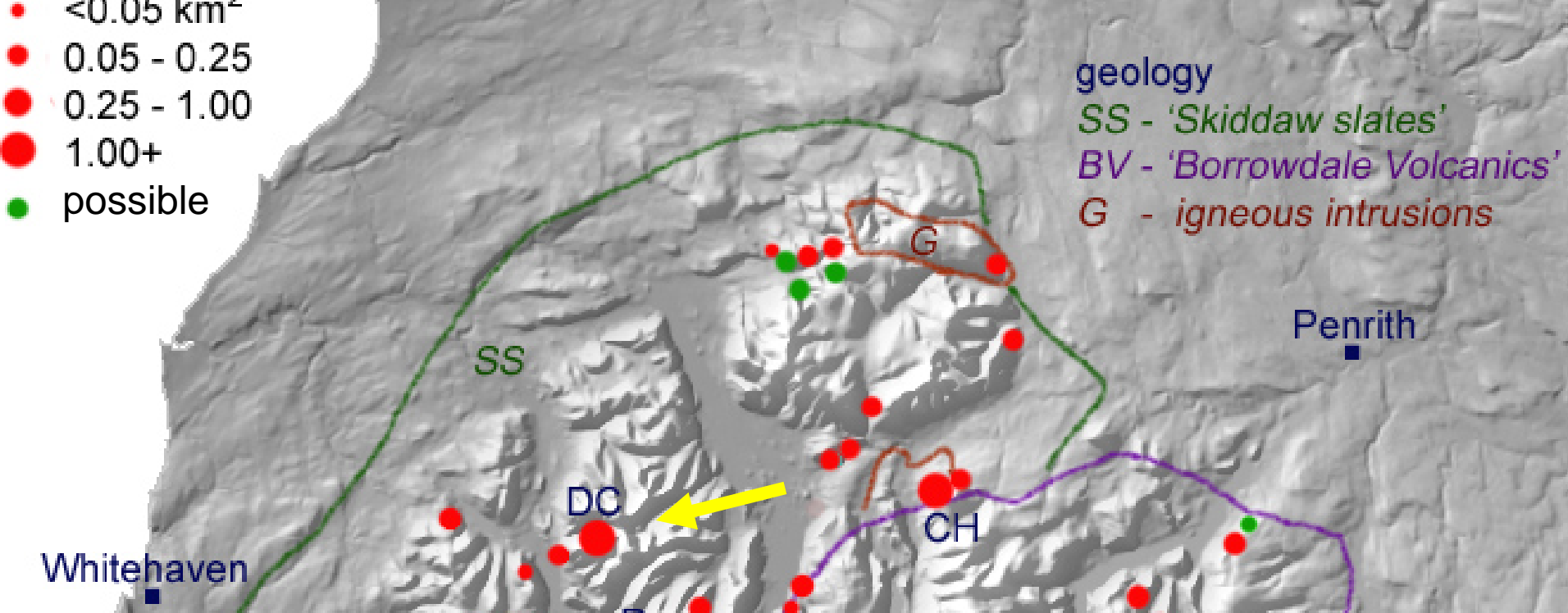

SS 3,3

1) $\frac{1}{4}$ - 2 G

BV - 'Borrowdale Volcanics'

$G$ - igneous intrusions

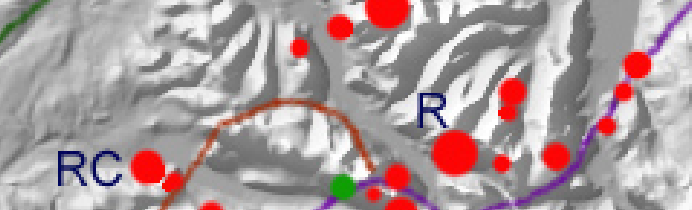

\section{Dove Crags - Gasgale Gill location \\ (arrowed)}

\section{RSF incidence in} the Lake District

all sites verified in the

field by the authors as definite or probable RSF, except where noted as 'possible'

BC Black Combe

$\mathrm{CH}$ Clough Head DC Dove Crags F Fairfield KF Kirk Fell

$\mathrm{R}$ Robinson RC Revelin Crag WC Whelter Crag

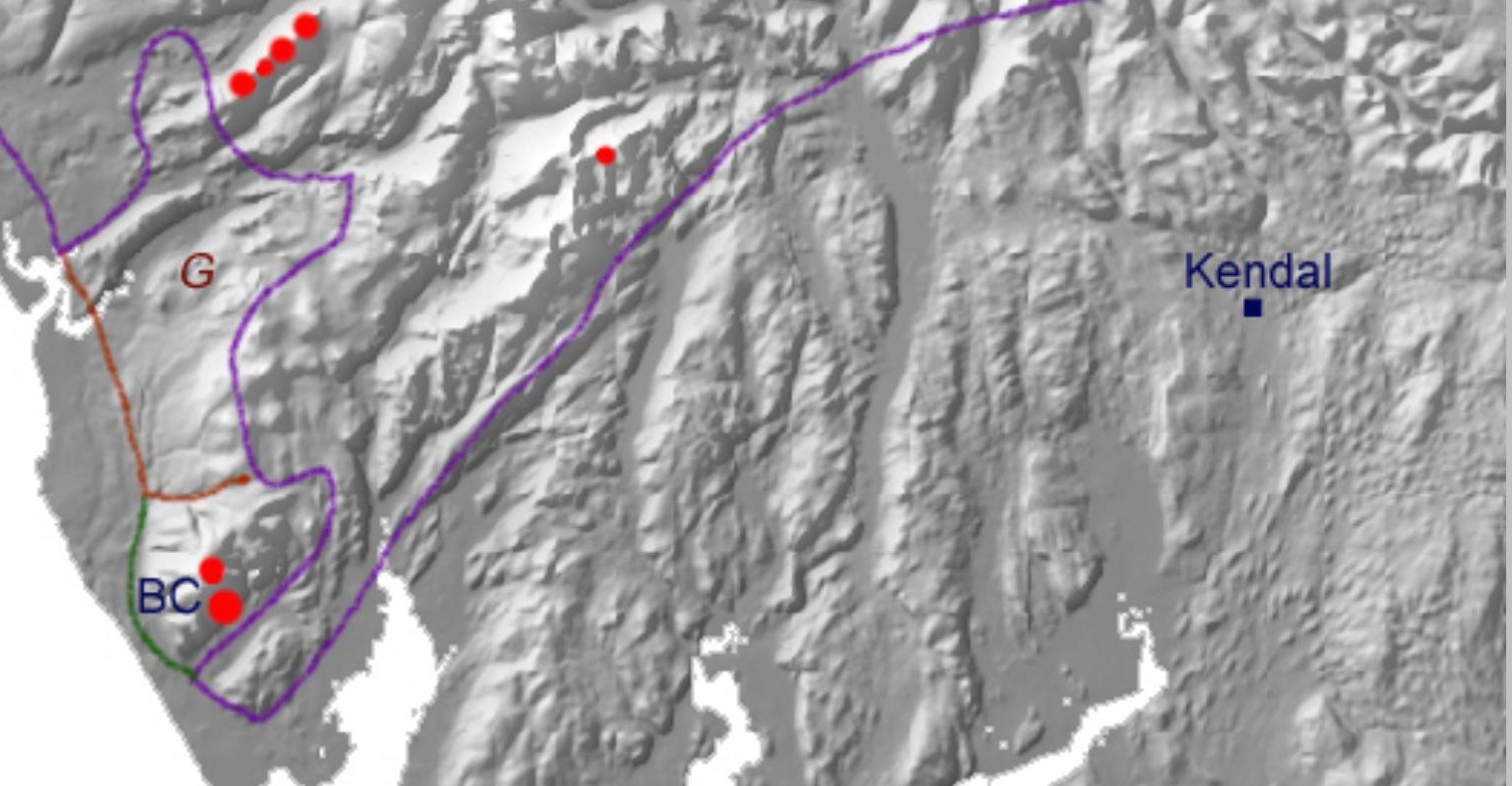

This is Fig 1 of the main paper 


\section{DOVE CRAGS RSF IN A LAKE DISTRICT CONTEXT}

- overall incidence of RSF in the Lake District is low compared with bolder Highland massifs, but greater than peripheral Highland areas (Jarman, unpublished data).

- within the Lake District RSF is sparse to absent in many parts - only other recorded RSF in the NW Fells north of Newlands Hause (cataclasmic deposits below steep, gullied west face of Grasmoor - Wilson 2011).

- even the Helvellyn-High Street and Ennerdale-Buttermere clusters affect less than 3\% of land area - cf. 6-10\% for Highland clusters of comparable extent.

- although 12 of the 70 Lakes RSFs are large $\left(>0.25 \mathrm{~km}^{2}\right)$, comparable with the Highlands, they are scattered.

- it is therefore hard to see a pattern in which to place Dove Crags, as an isolated large site.

RSF incidence seems to associate with locales with recent concentrated erosion of bedrock (CEB - Jarman 2006). Two main CEB locales into which Dove Crags might fit are :

\section{glacial breaches}

- most RSFs in dissected central / western Lake District are associated with glacial breaches and trough walls down-ice from them, e.g. Dale Head and Robinson (Wilson \& Smith 2006), on N flank of large Honister Pass breach, and Burnbank Fell beside Loweswater diffluent breach (SI-03).

- however, at head of Gasgale Gill, Coledale Hause is a high paleic col (600 m OD) with minimal evidence of transfluent ice to augment erosion (SI-36).

- this is consistent on NW Fells watershed (SI-03): Sail Beck Hause 'paleic' col 465 m; Newlands Hause 330 m lowered $\sim 20 \mathrm{~m}$ by minor breaching; only Honister and Whinlatter Passes substantially enlarged by breaching down to 355 and $315 \mathrm{~m}$ OD.

- Dove Crags is thus not a glacial breach CEB locale.

\section{trough heads}

- in E Lake District, breaching is minimal, RSFs in Helvellyn / High Street clusters associate with flanks of side-

troughs with closed heads - inferred to be 'late developers' in a precipitation lee, still enlarging later Pleistocene.

- Dove Crags is a typical side-trough-flank locale - its confined 'hanging' character has affinities with upper

Grisedale and Hartsop side valleys in E Lakes.

- Scope End RSF on NE Hindscarth ridge (previously unreported) is also on flank of a side trough (Fig. SI-03). 


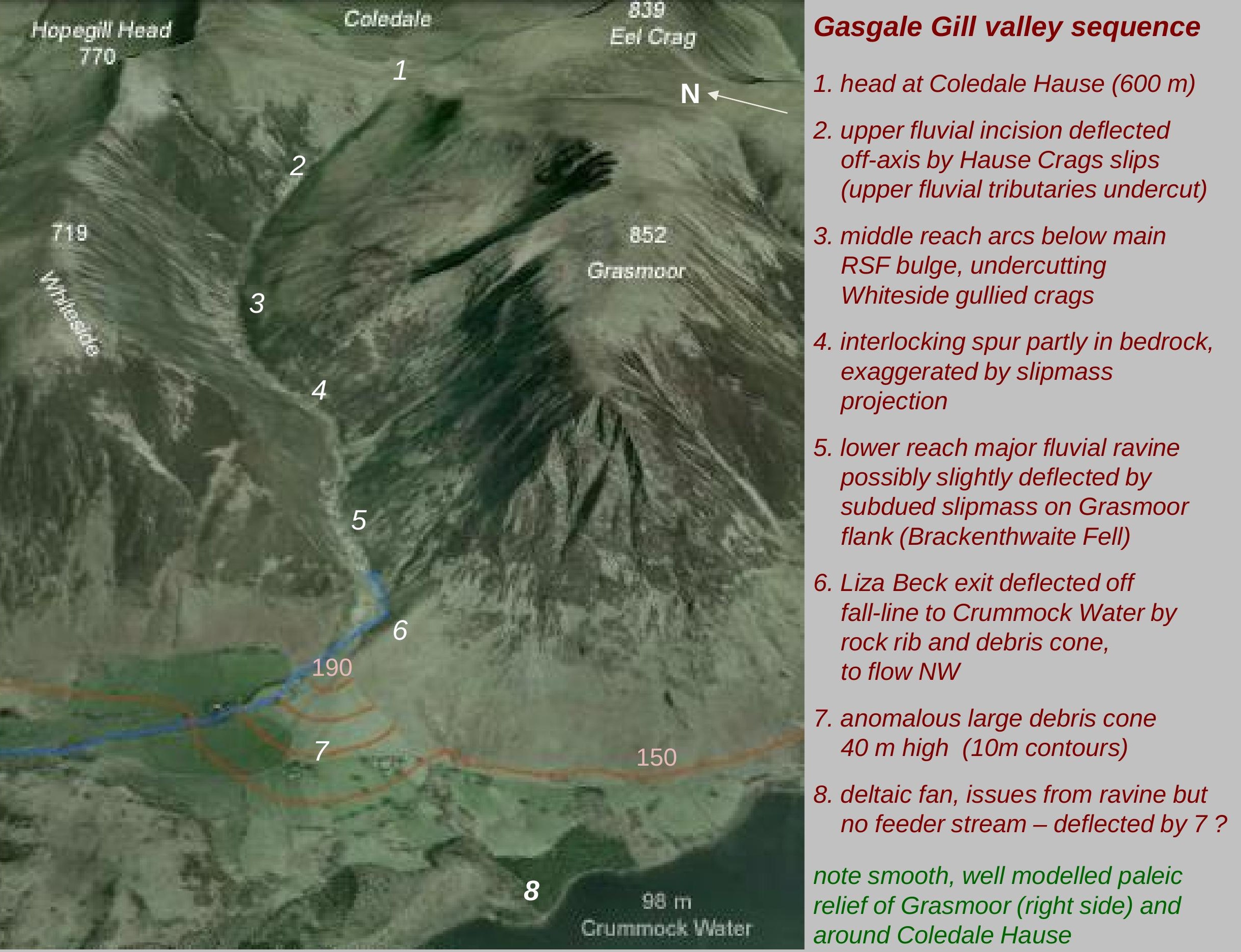



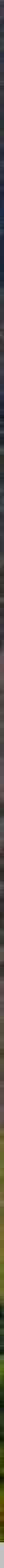

Gasgale Gill fluvial character - headwaters
- interlocking spurs

- ravine exit
BF - Brackenthwaite Fell cavity 
outer edge of Dove Crags mass movement failed mass displacing valley axis north, promoting erosion of opposite side

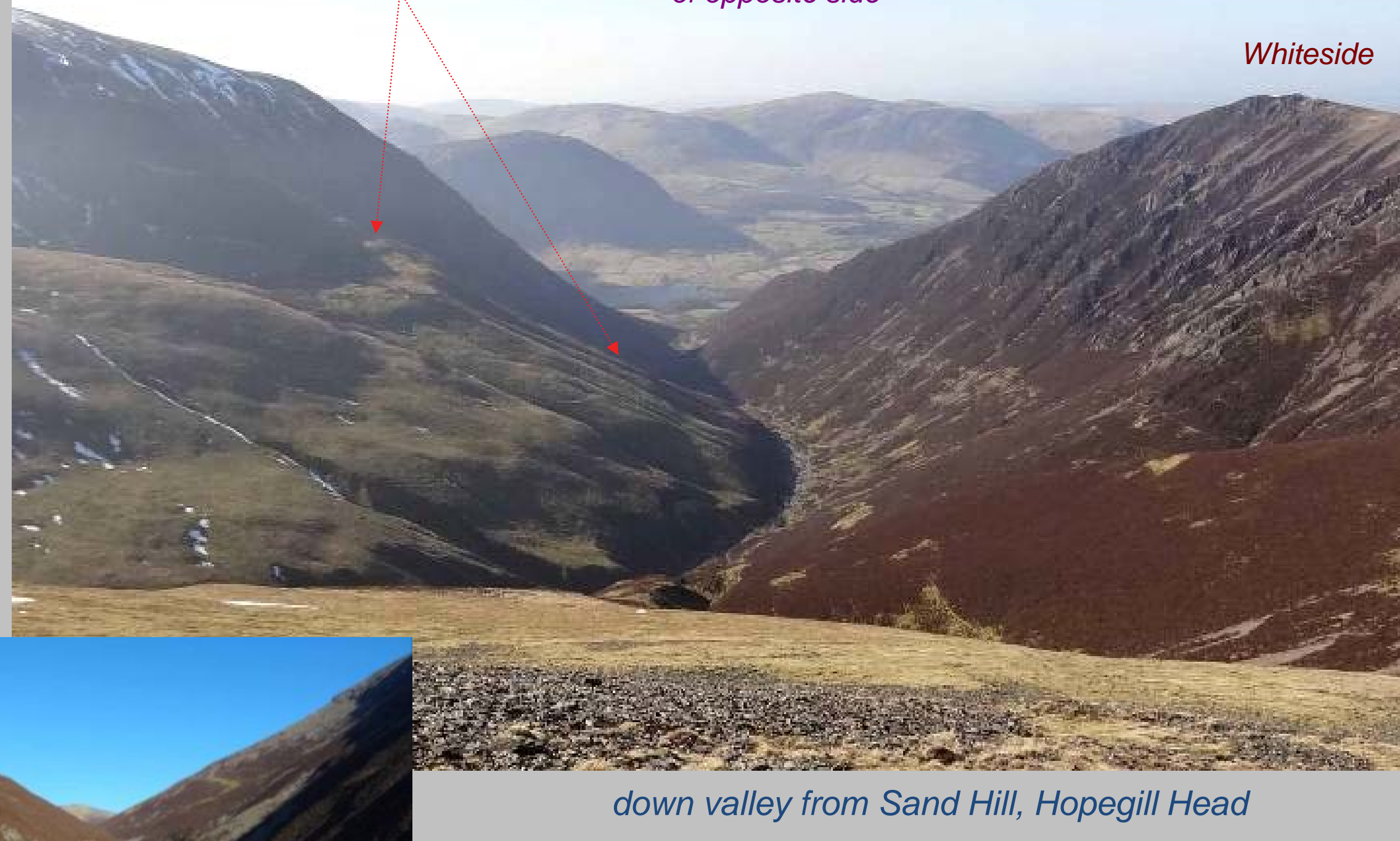

Gasgale Gill hanging valley into Buttermere--Lorton trough

deeply incised, long-adjusted fluvial exit ravine 


\section{Whiteside}

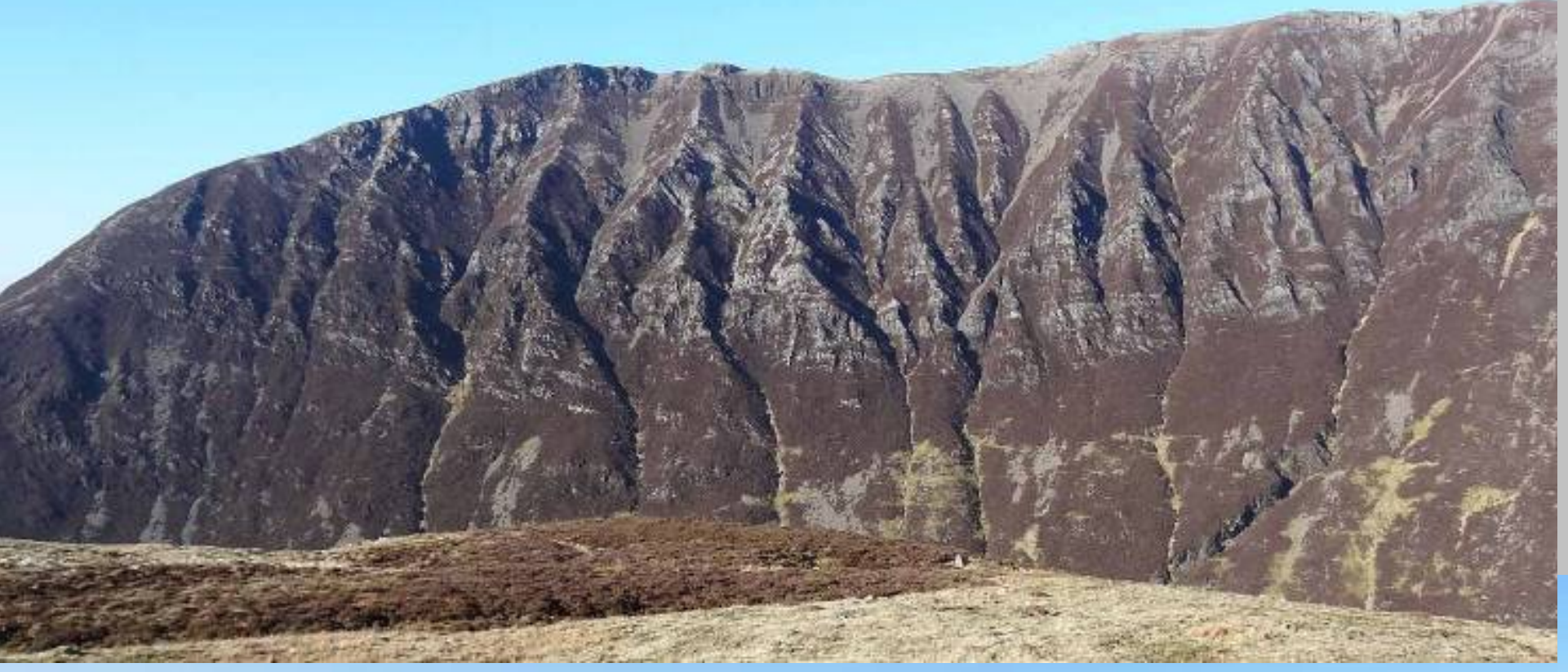

anomalously steep and gullied in Skiddaw 'slates' (Gasgale Crags)

Gasgale Gill marked asymmetry from head below Coledale Hause

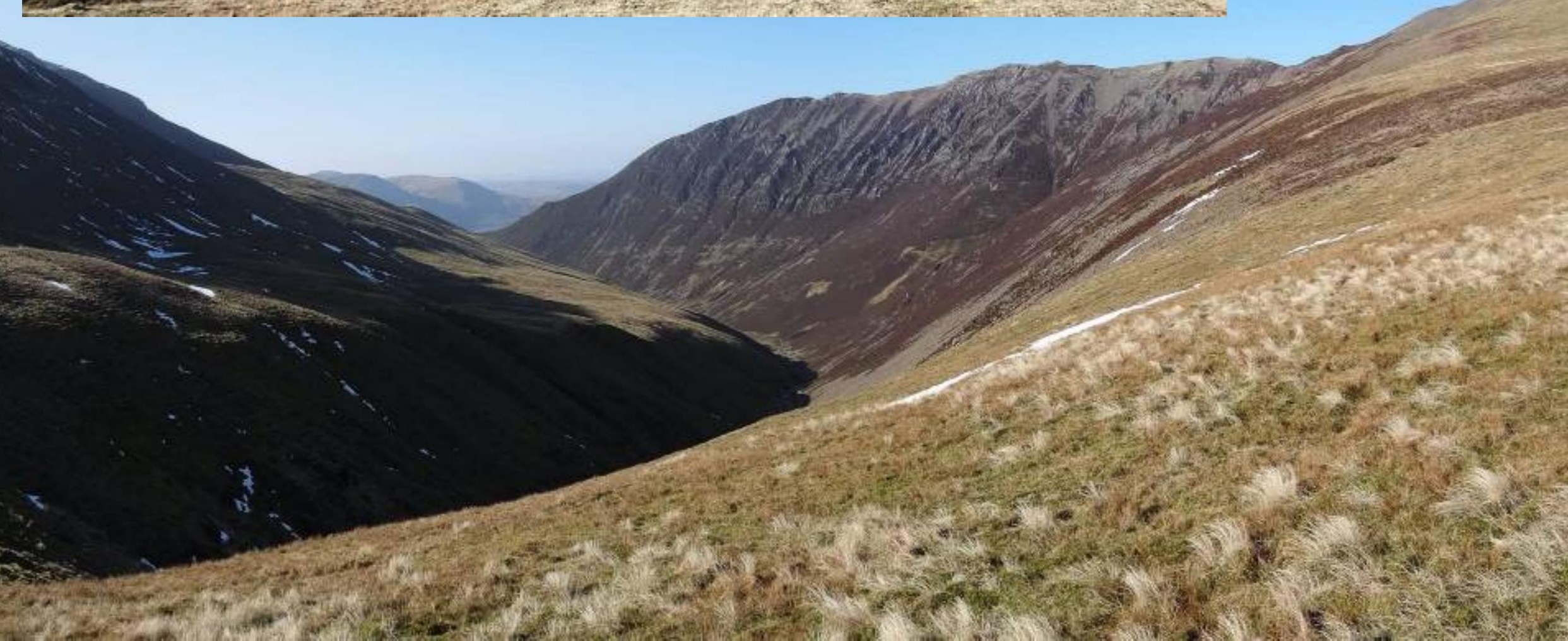




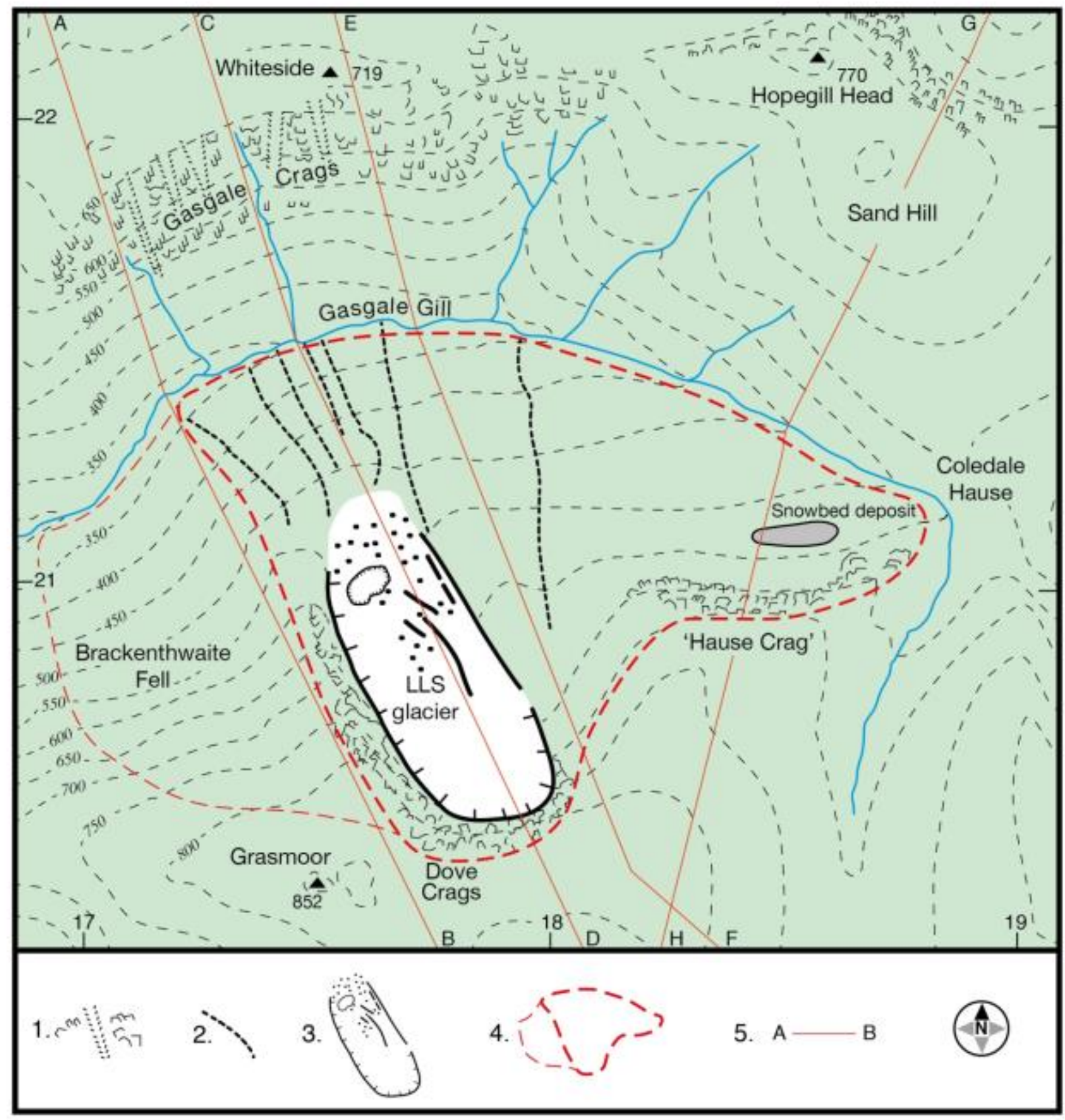

\section{Dove Crags 'cirque'}

LLS glacier extent (white) is reasonably well constrained by moraines

1. cliffs, outcrops and gullies

2. dry channels

3. moraine ridges, dry hollow in cavity floor

4. proposed RSF extent (bold) with adjacent possible RSF (faint)

5. cross-sections

(Fig 8 in main paper)

this is Fig 3 in main paper 


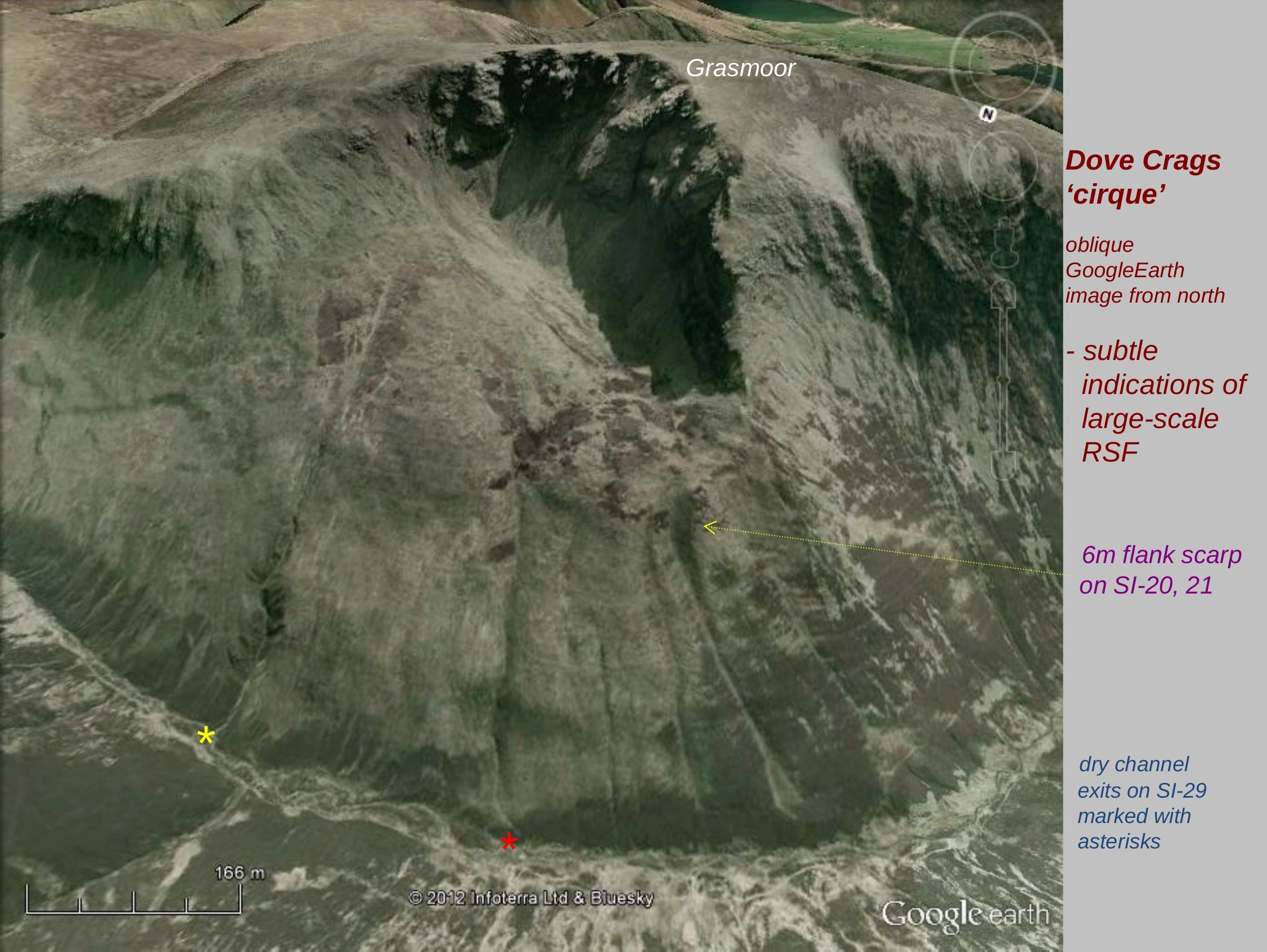




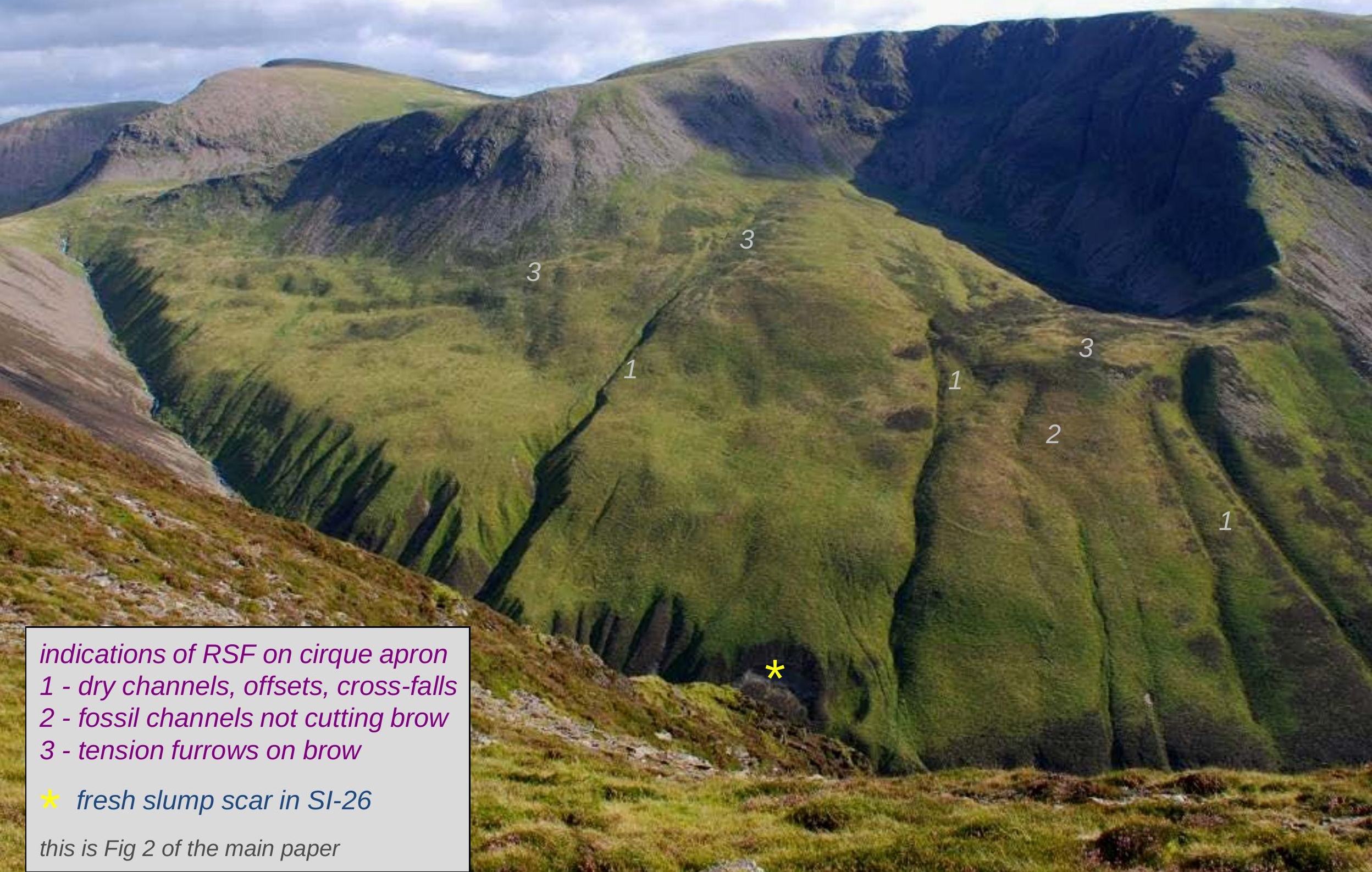



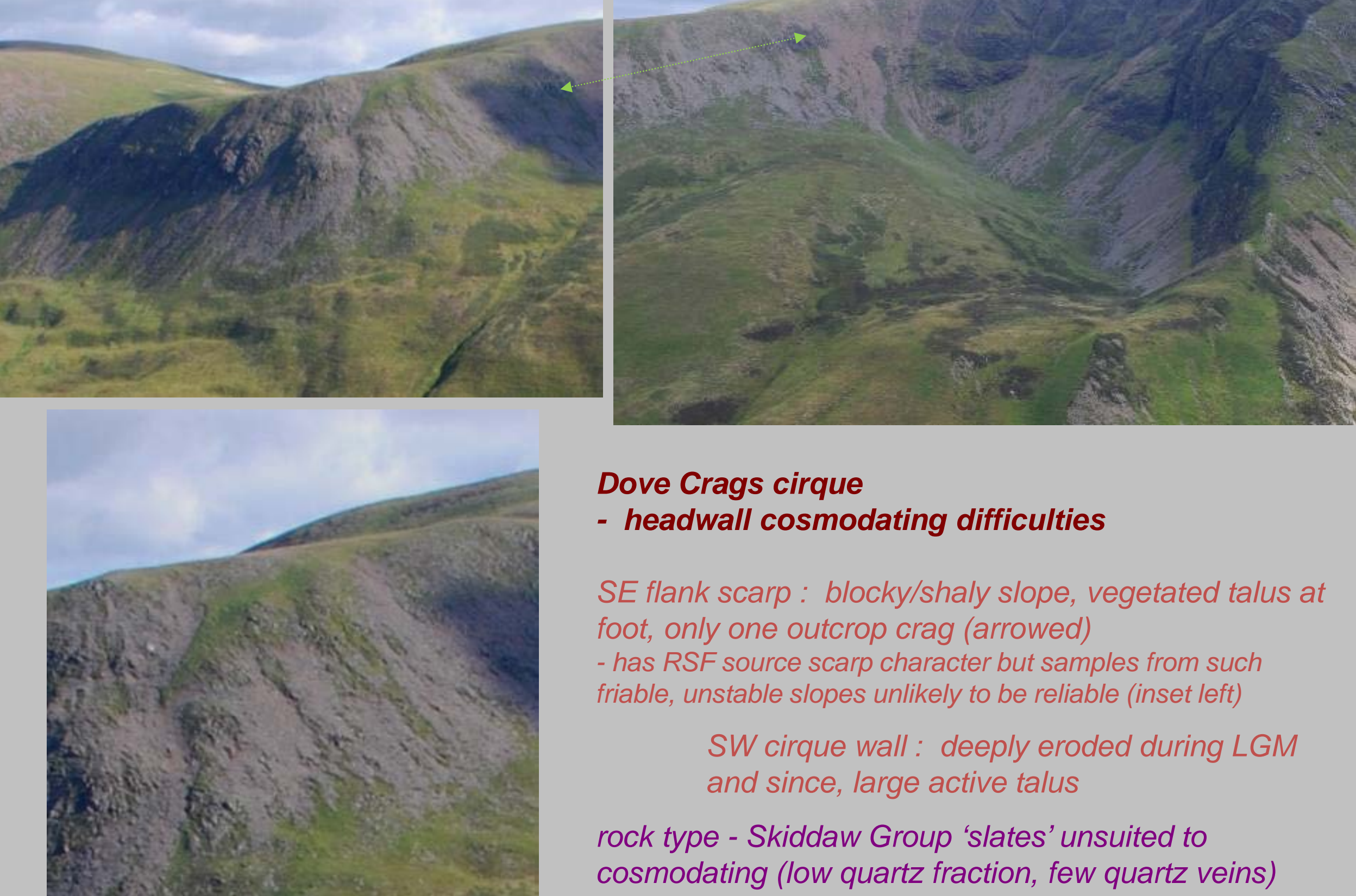

\section{Dove Crags cirque}

- headwall cosmodating difficulties

SE flank scarp : blocky/shaly slope, vegetated talus at foot, only one outcrop crag (arrowed)

- has RSF source scarp character but samples from such friable, unstable slopes unlikely to be reliable (inset left)

SW cirque wall : deeply eroded during LGM and since, large active talus

rock type - Skiddaw Group 'slates' unsuited to cosmodating (low quartz fraction, few quartz veins) 



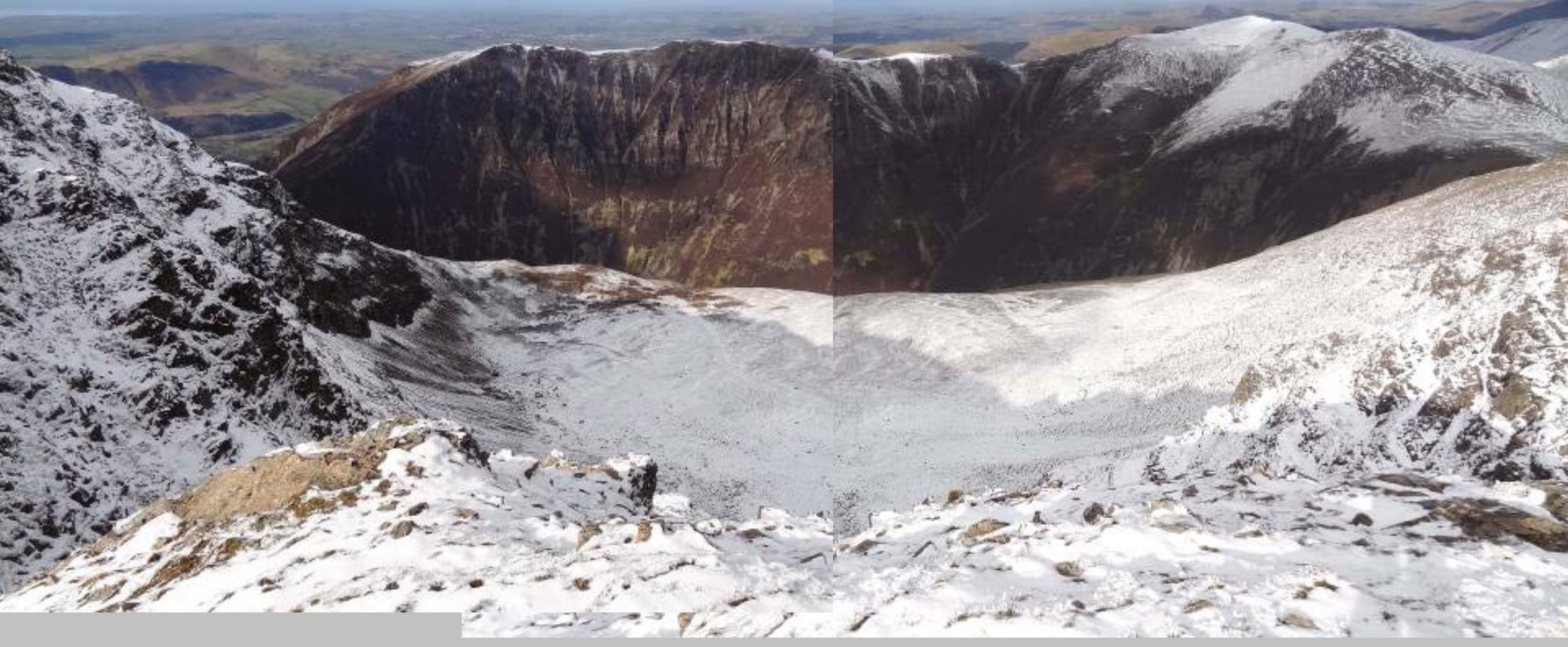

Dove Crags cirque from Grasmoor plateau rim

- threshold projects slightly into Gasgale Gill valley

- lower (left / west) side projects further

Whiteside asymmetric ridge and gullied craggy trough wall opposite

W Cumberland plain beyond 
LLS moraine down the convexity flank
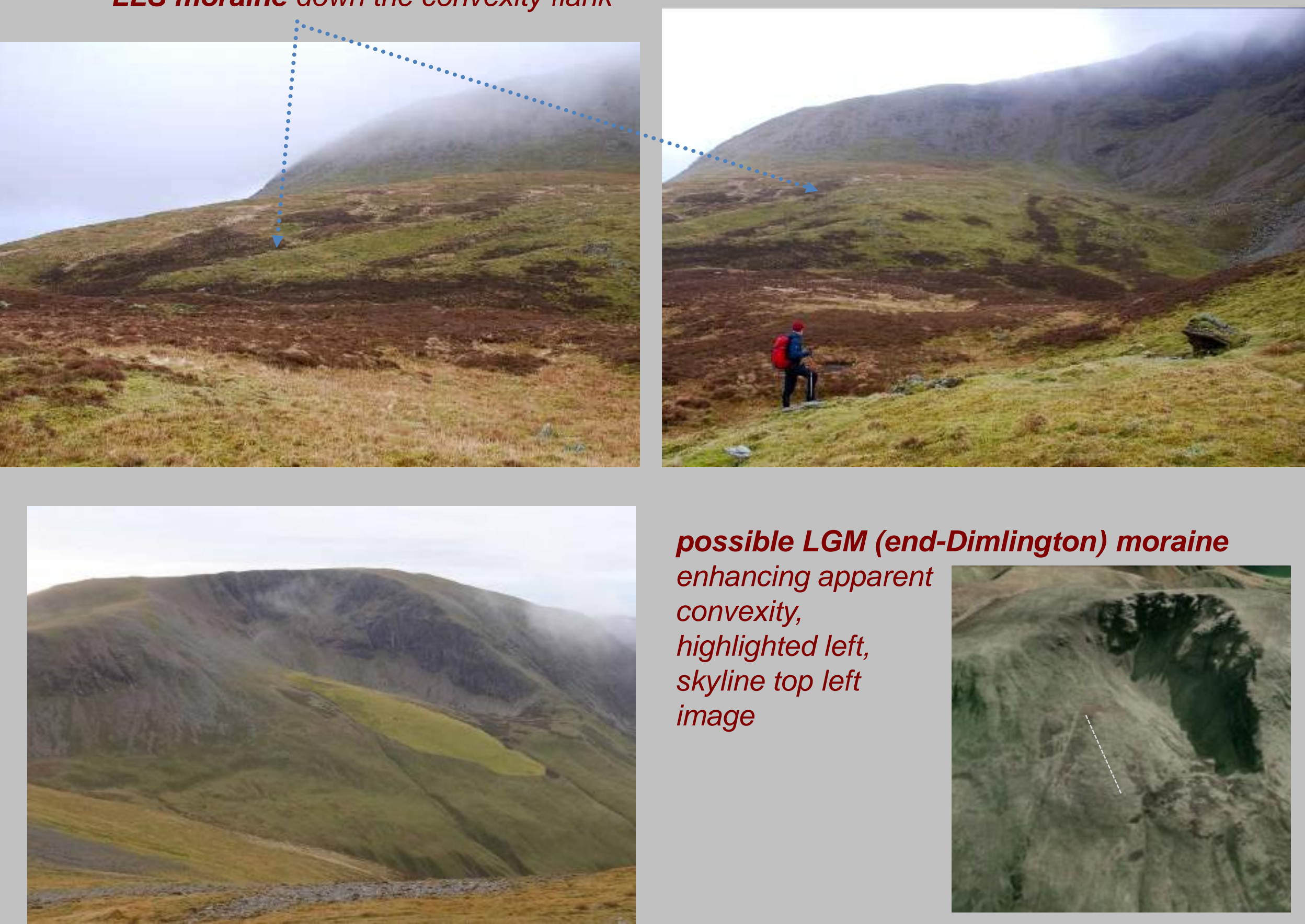

possible LGM (end-Dimlington) moraine enhancing apparent convexity, highlighted left, skyline top left image

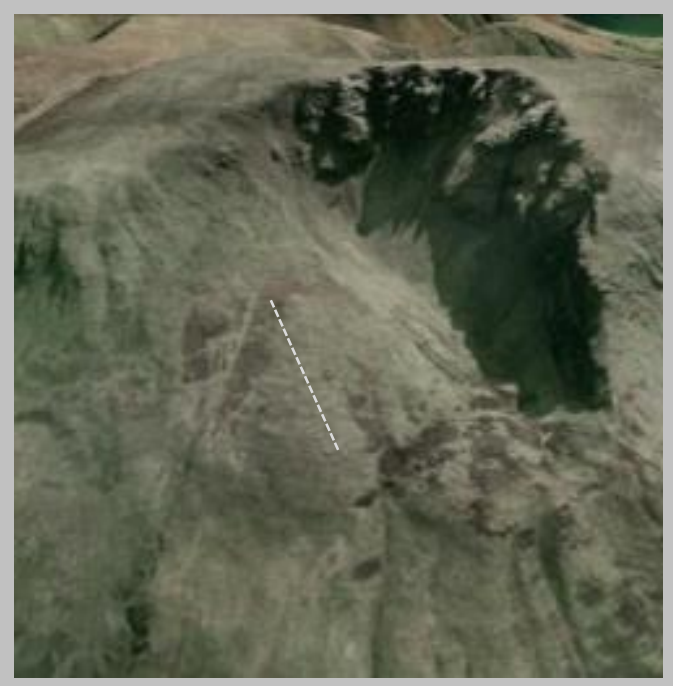



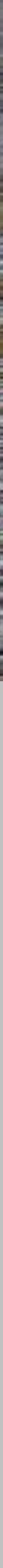

the tarnless hollow below Dove Crags

closed contour basin asterisked 



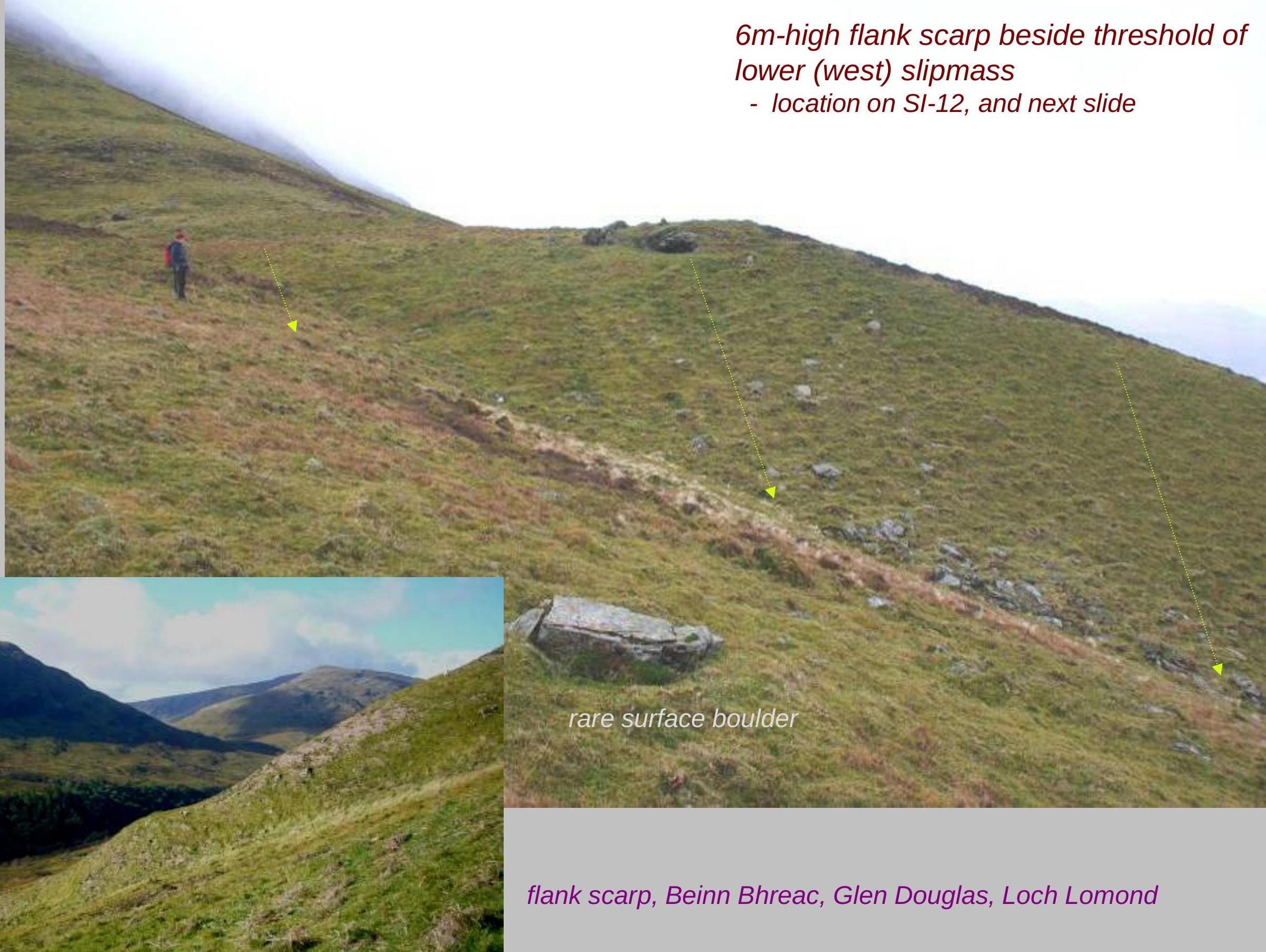




\section{Brackenthwaite Fell concavity}

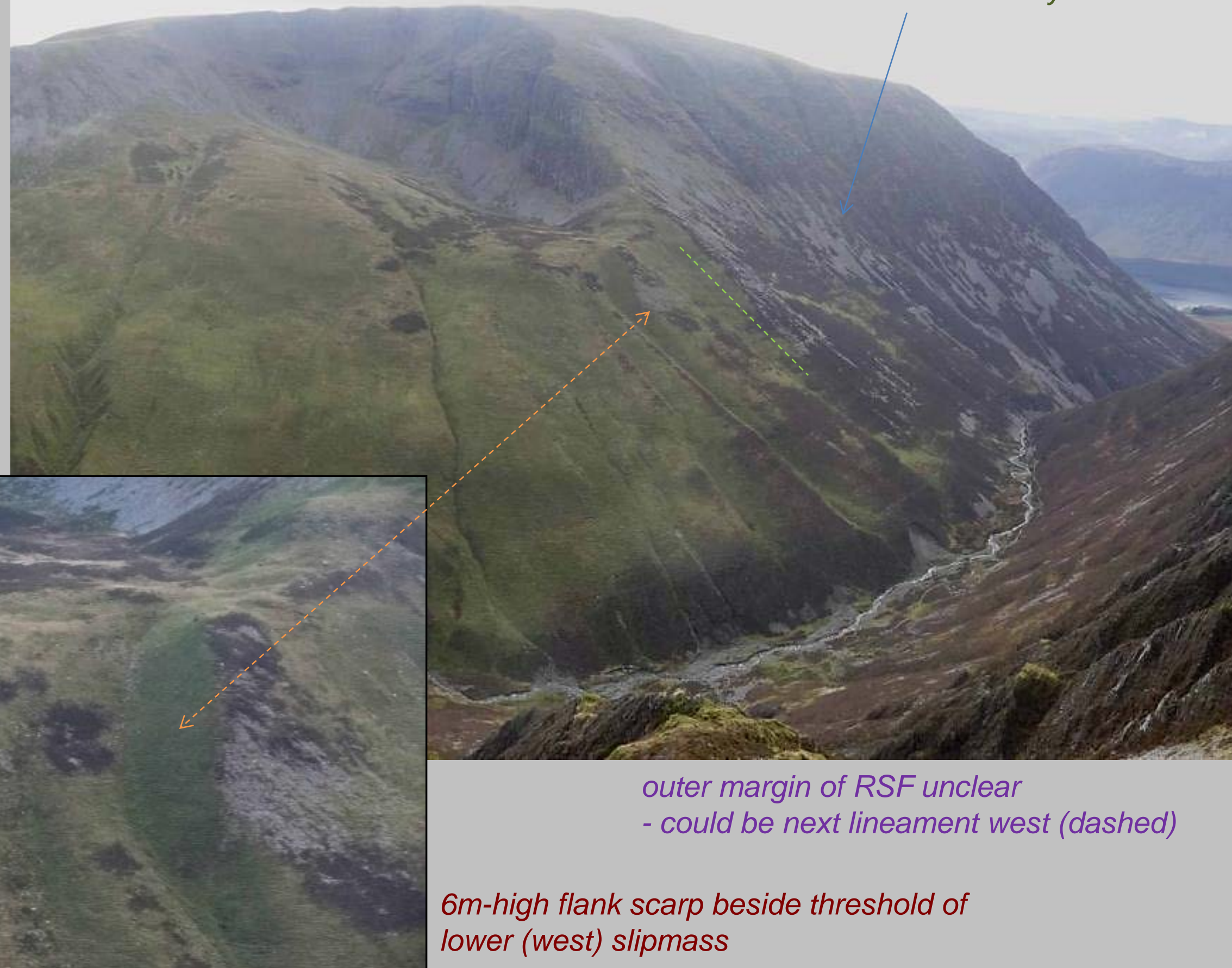




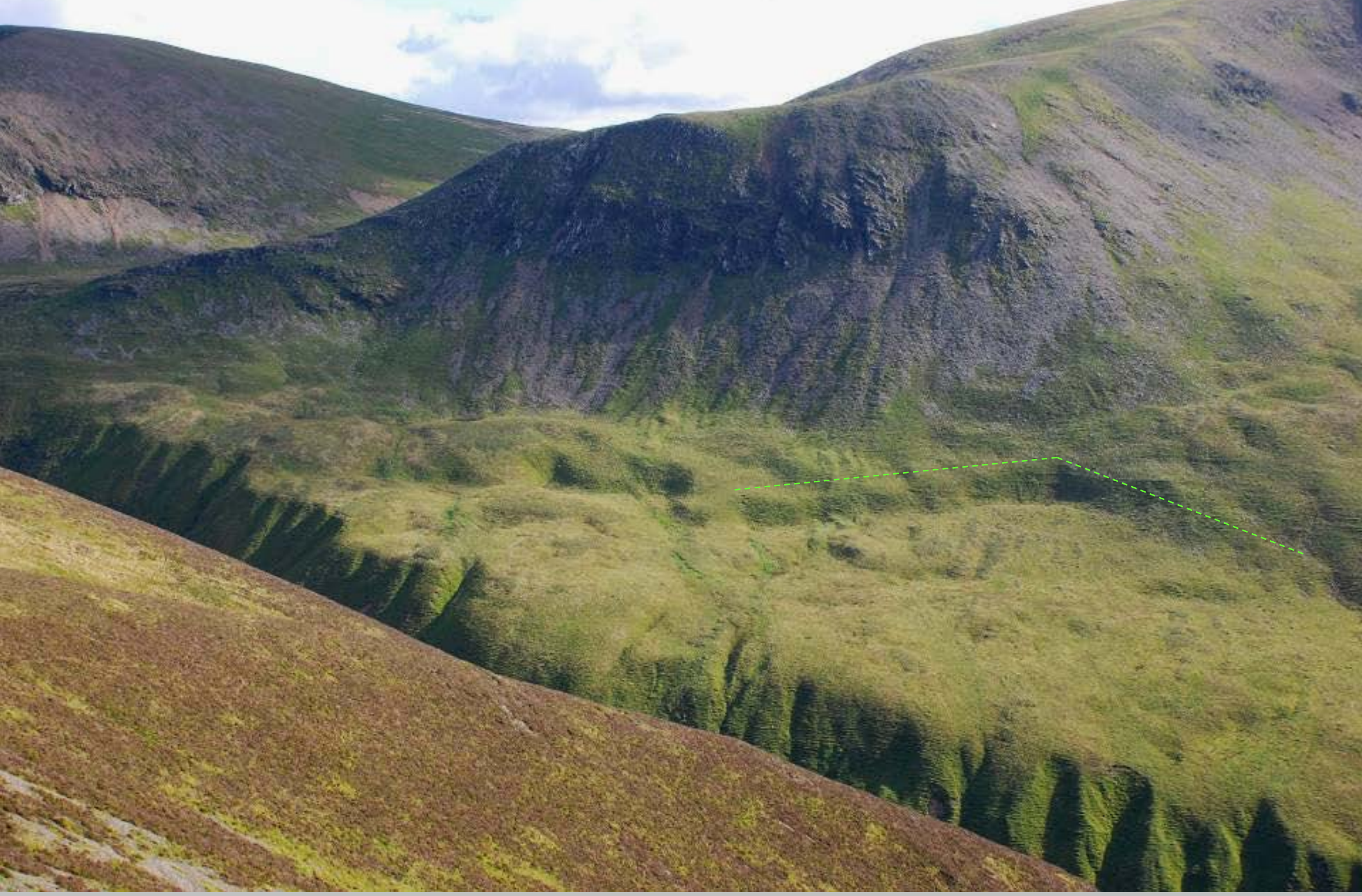

Hause Crag scar and slipmass

- Sissons 'snowbed deposits' superimposed on slipmass

- secondary wedge scarp invades these deposits (marked green)

this is the source for Fig. 6 (main paper) 


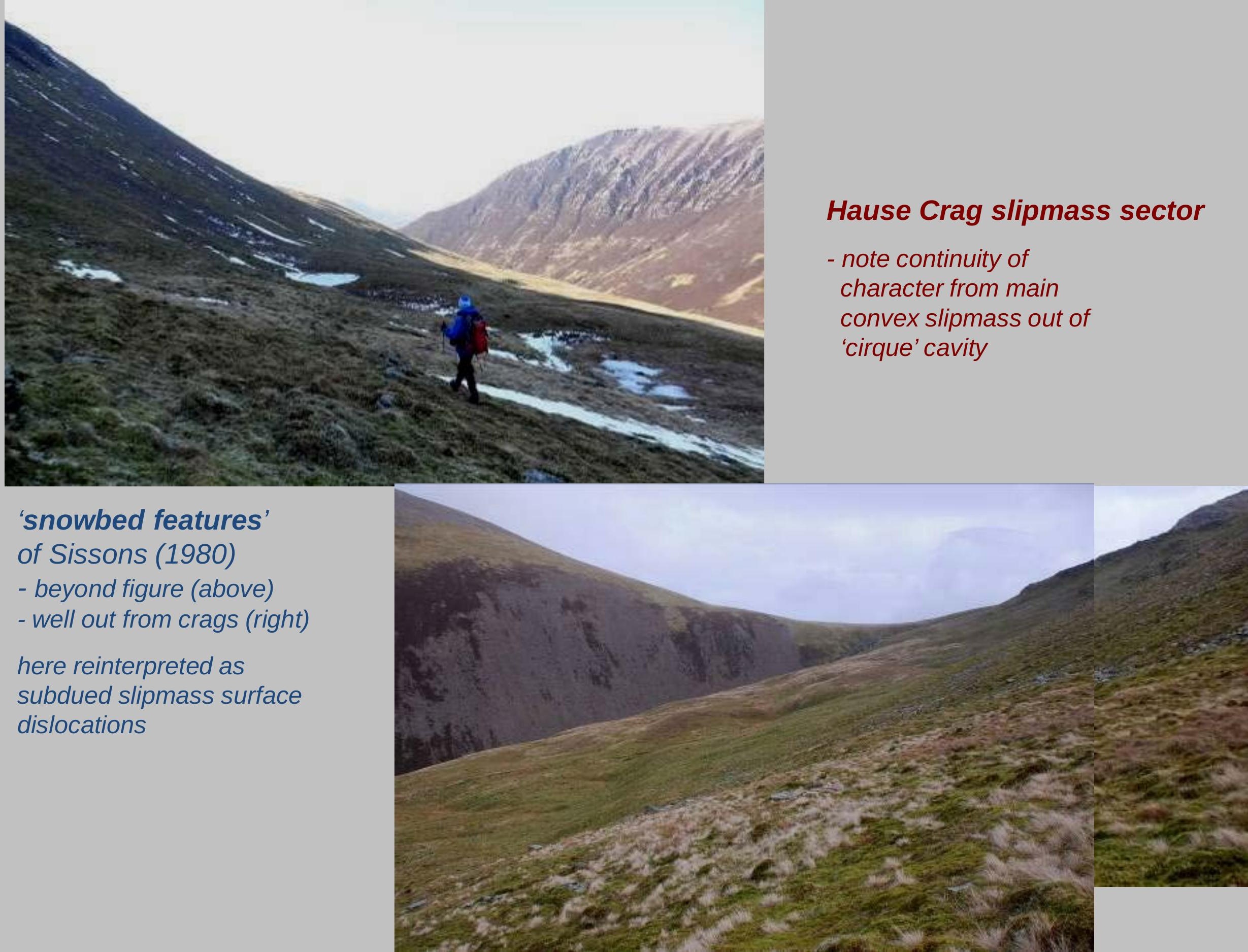




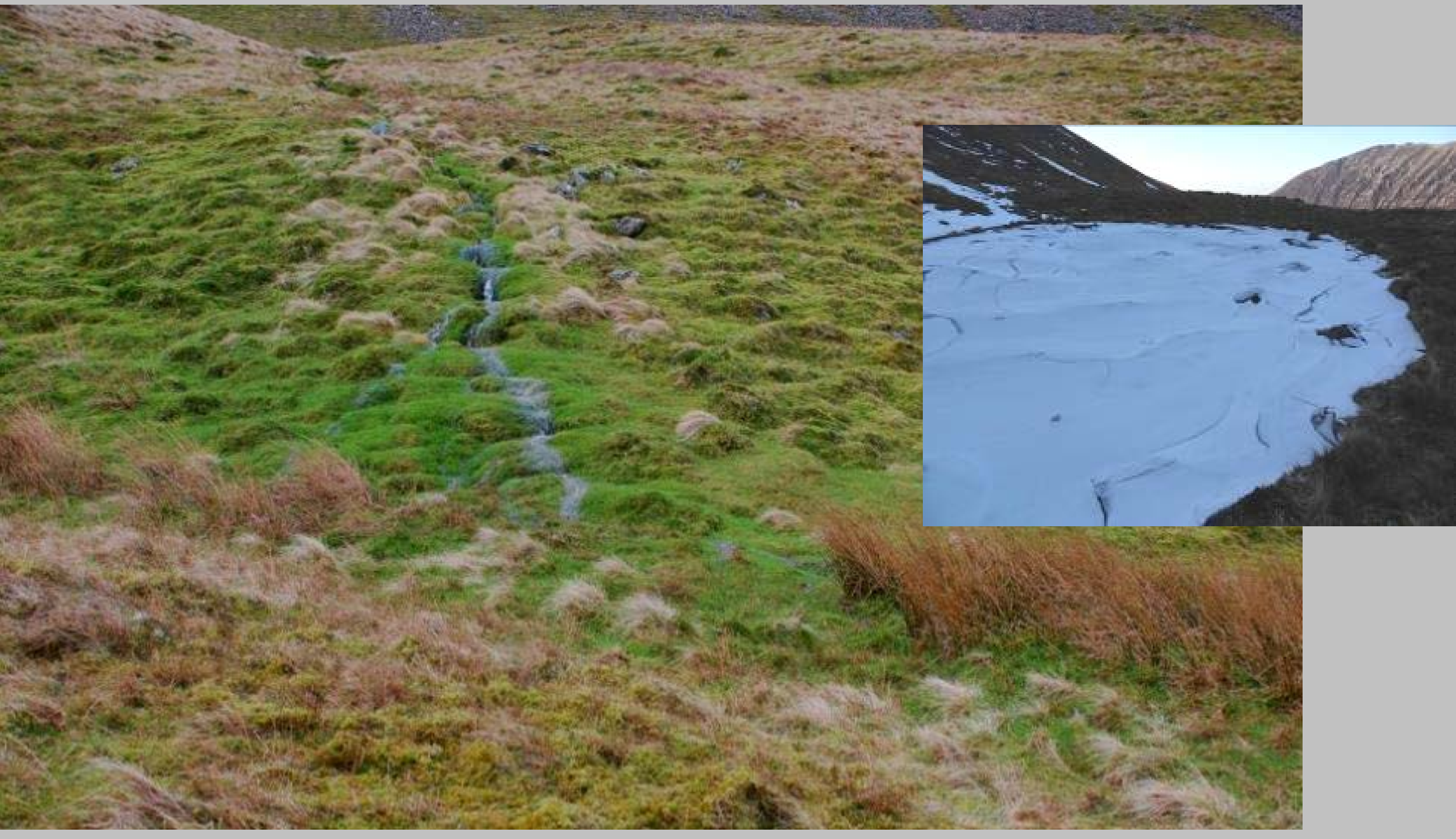

surface drainage from ephemeral pool (inset) within snowbed hollows of Sissons (1980) - flows over surface - sinks in rushes 


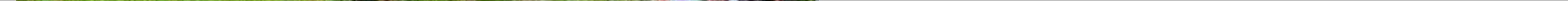




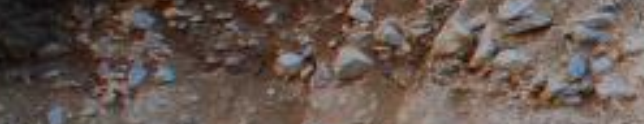

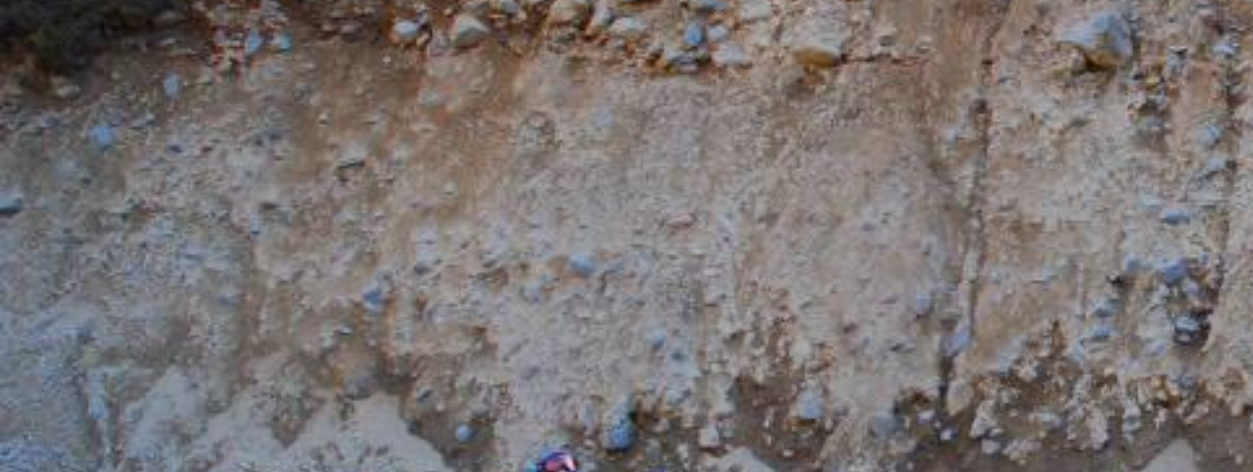
15.

stost:

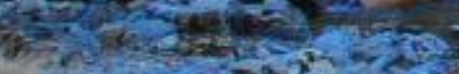

85
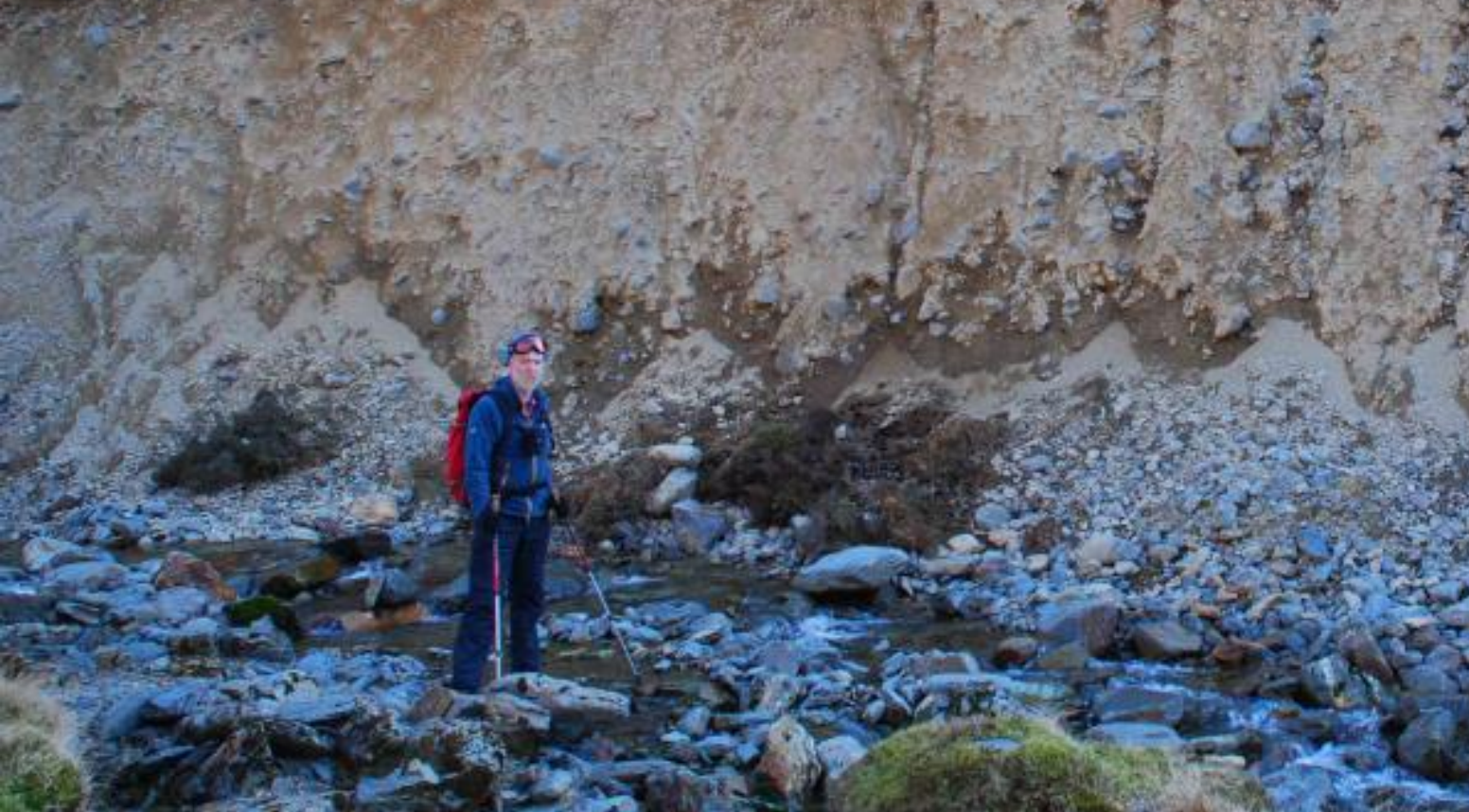

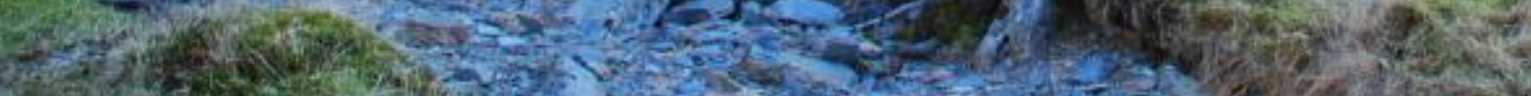
-
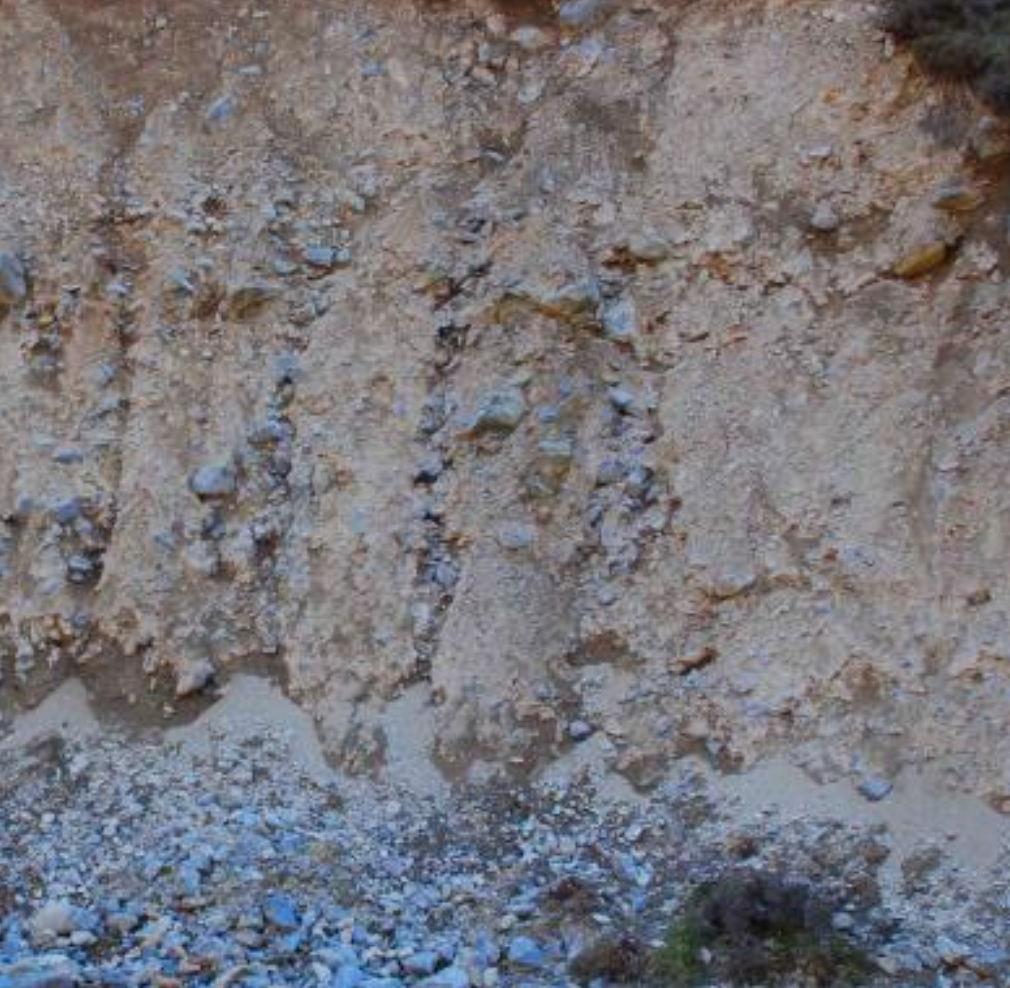

$4 \cos ^{2}$
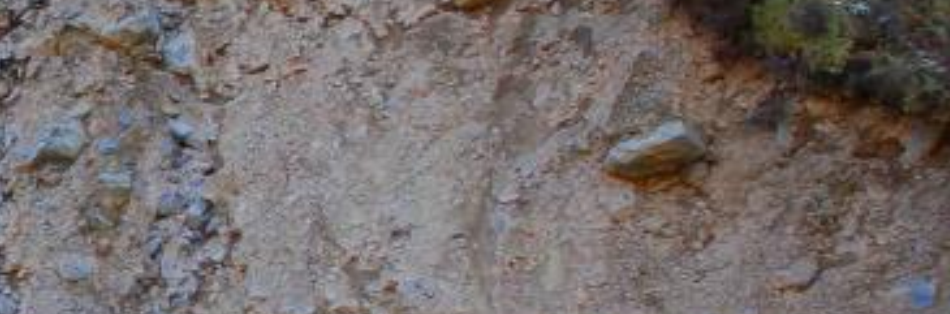




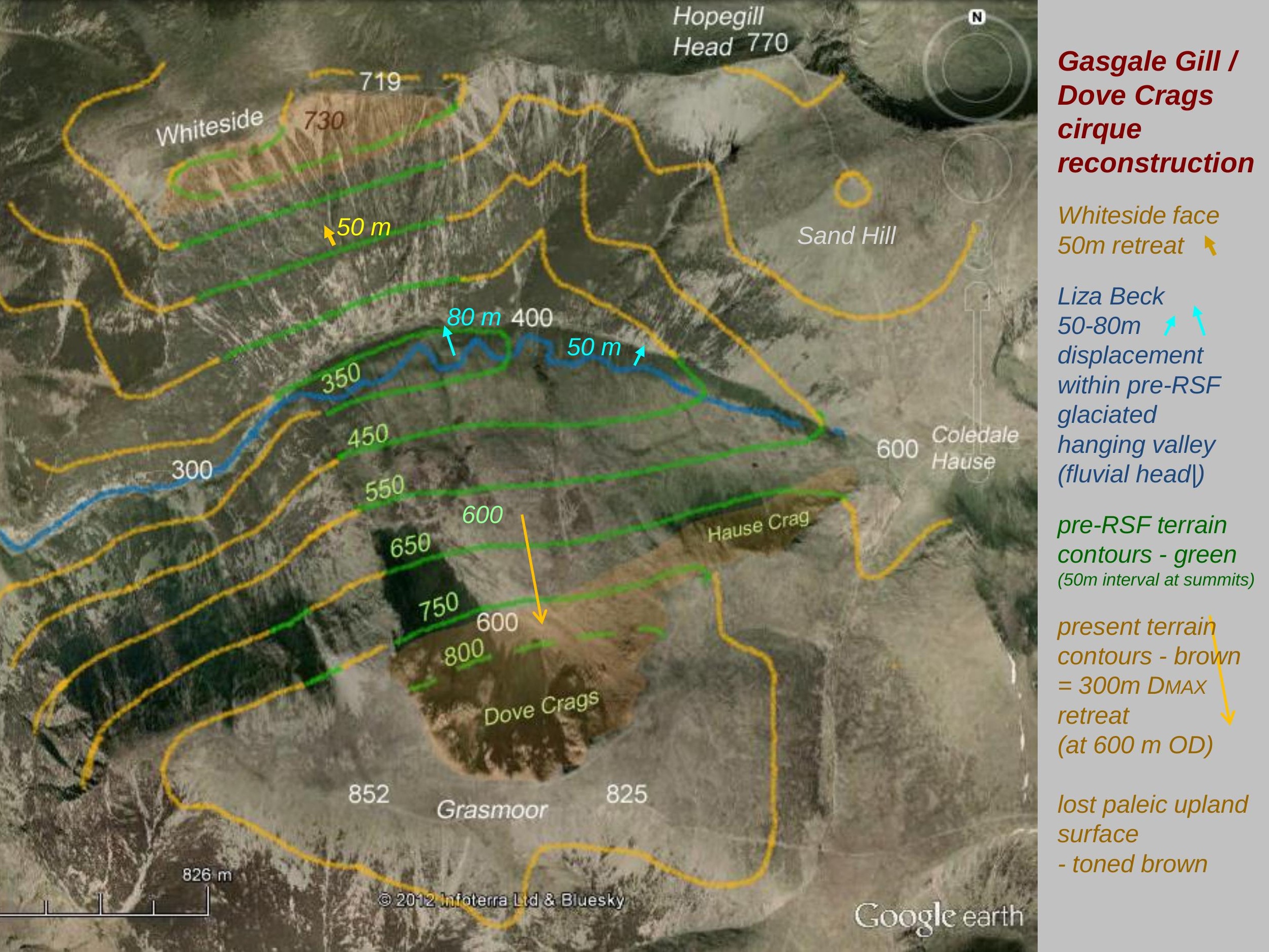




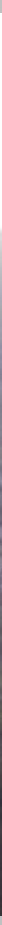

reinstatement of Hause Crag and Dove Crags slipmasses (arrowed) achieves matching preglacial forms around Gasgale Gill valley head

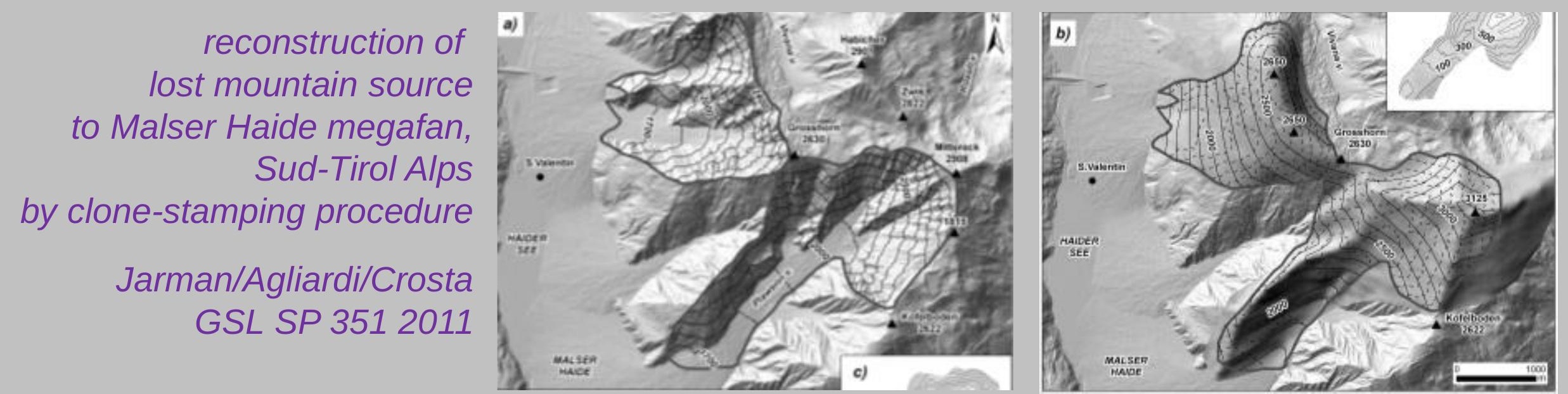


- created by Gasgale Crags truncating

Hopegill Head gentle north slopes of paleic ridge

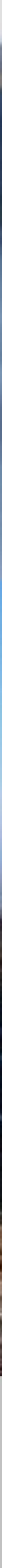




\section{Whiteside ridge reconstructed}

- slightly-domed paleic ridge, lowered by $\sim 10-20 \mathrm{~m}$ - invaded by Gasgale Crags, valley-wall retreat $\sim 50 \mathrm{~m}$

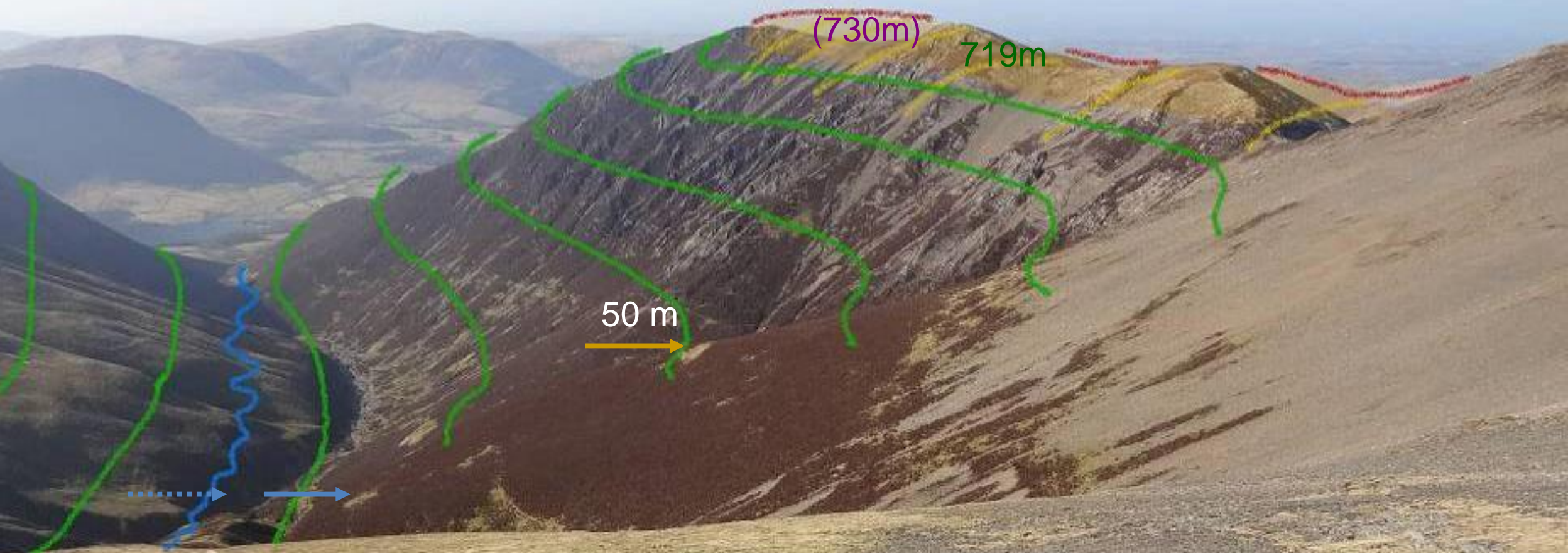

\section{6.}

\section{Gasgale Gill} valley evolution

Liza Beck displaced east in stages by Dove Crags slipmass

view down Hopegill Head SW fluvial head suggests offset valley axis

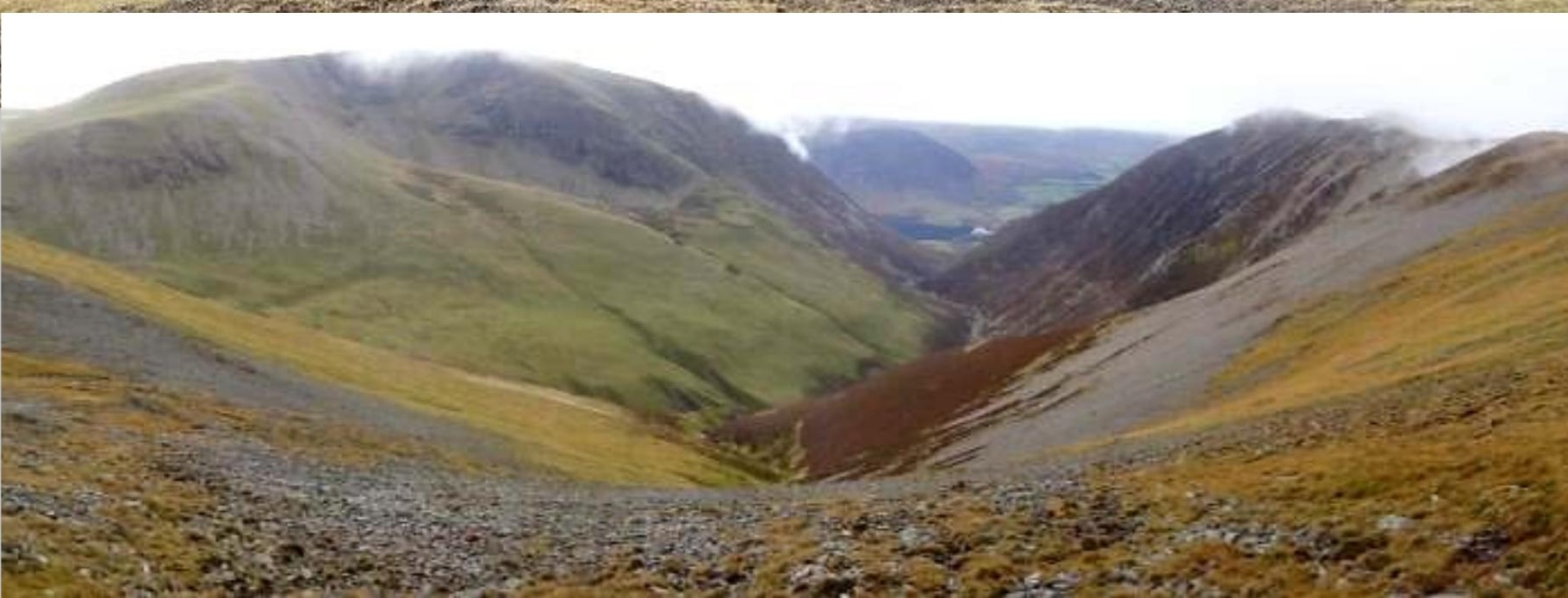


Eel Crag / Crag Hill

stream off plateau in open fluvial channel, now captured by Gasgale Gill (former route arrowed)

Coledale Hause from paleic slopes of Sand Hill (above) and from Whiteside (right)

- Hause (col) shows minimal signs of glacial breaching or Quaternary divide displacement (Tertiary $\sim 1 \mathrm{~km} \mathrm{E)}$

Eel Crag / Crag Hill

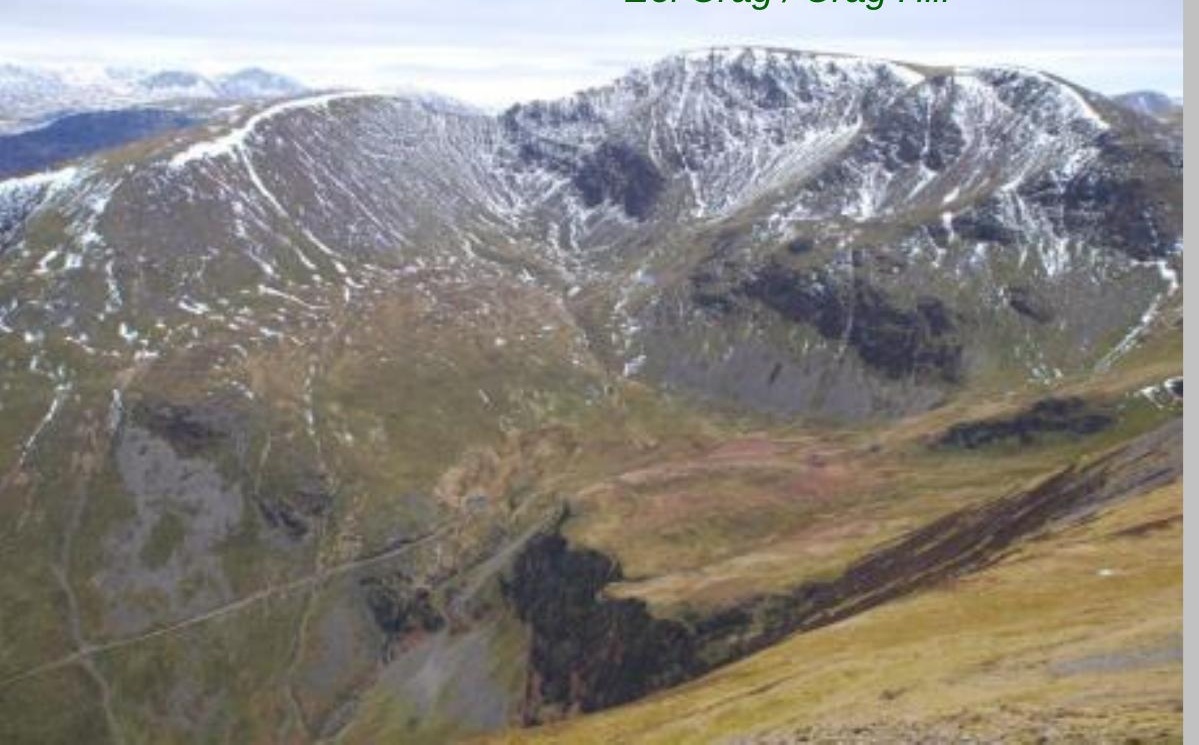

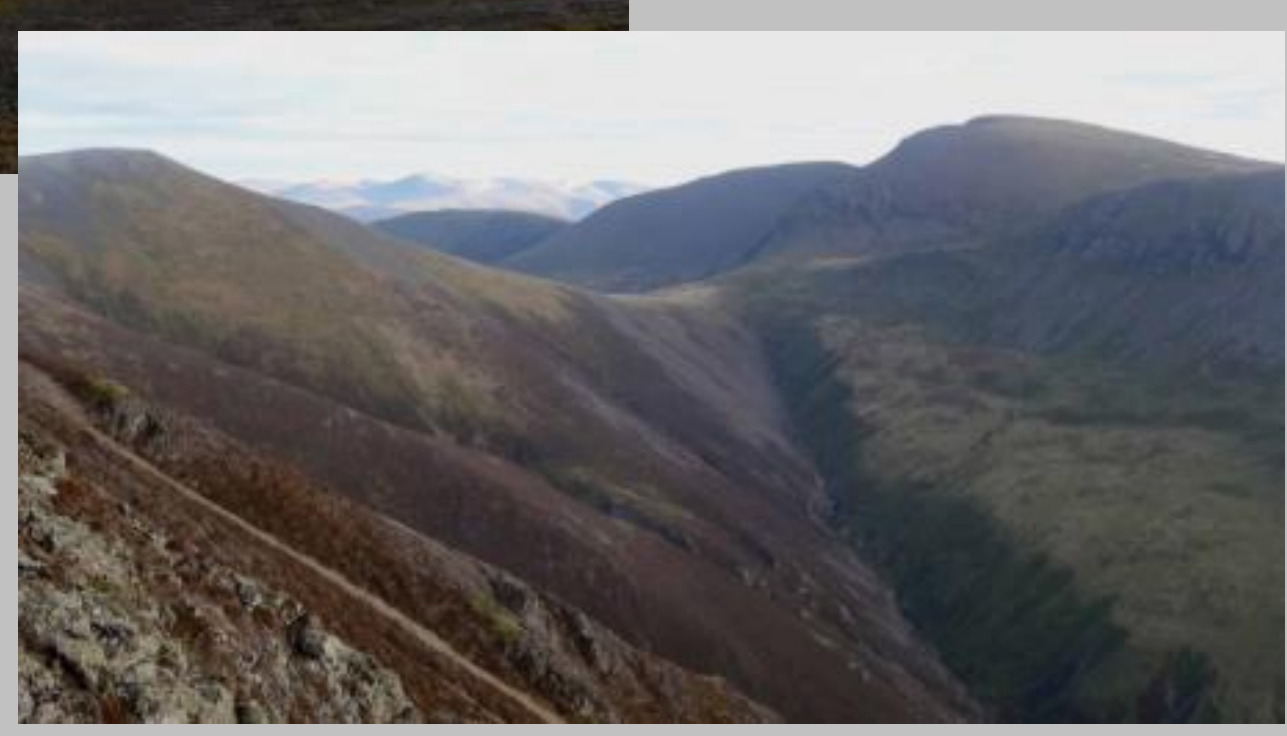

cirqueplex of Eel Crag / Crag Hill at head of Coledale

- more conventional glaciated form

- $\quad$ some affinities with Dove Crags, notably convex form below planar flank scarp 


\section{Hope Gill}

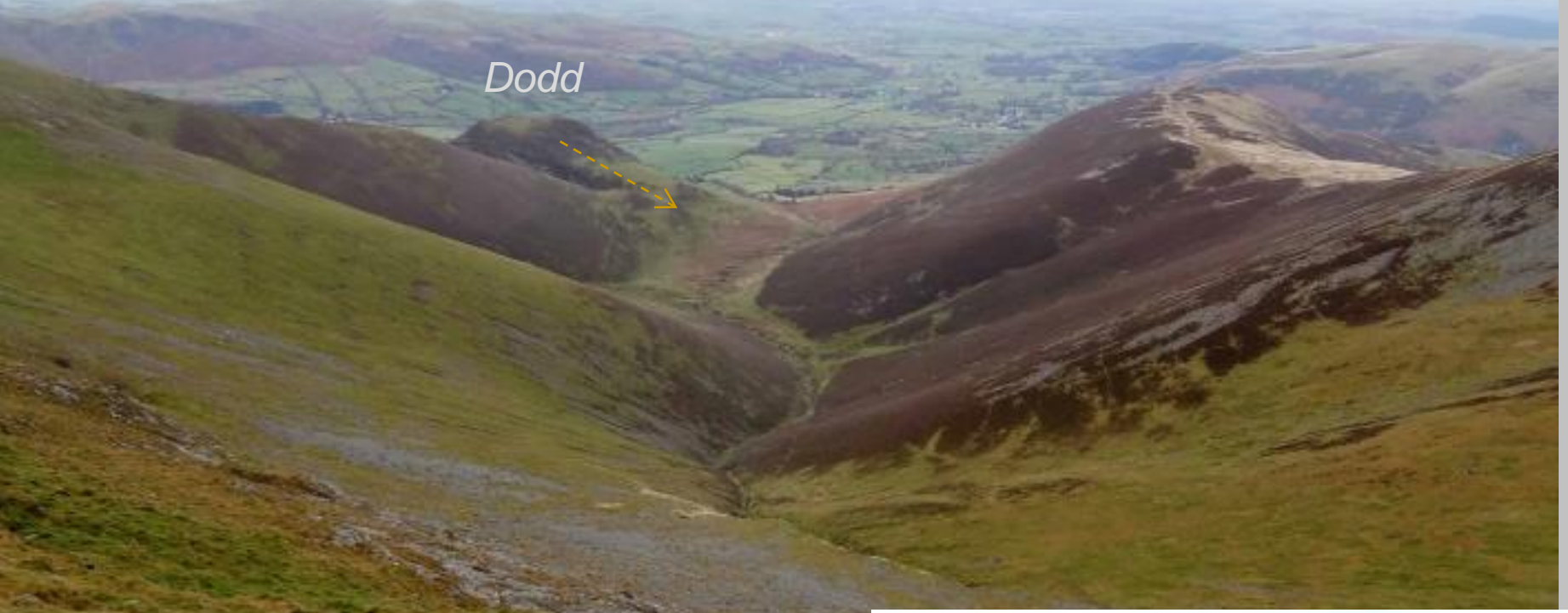

- fluvial valley north of Whiteside

- Dodd anomalous scarp, projecting deposits

- too large to result from glaci-fluvial nick

- inferred RSF, smallscale version of Dove Crags?

- age ? - dissected by LGM meltwaters

location HG, next slide
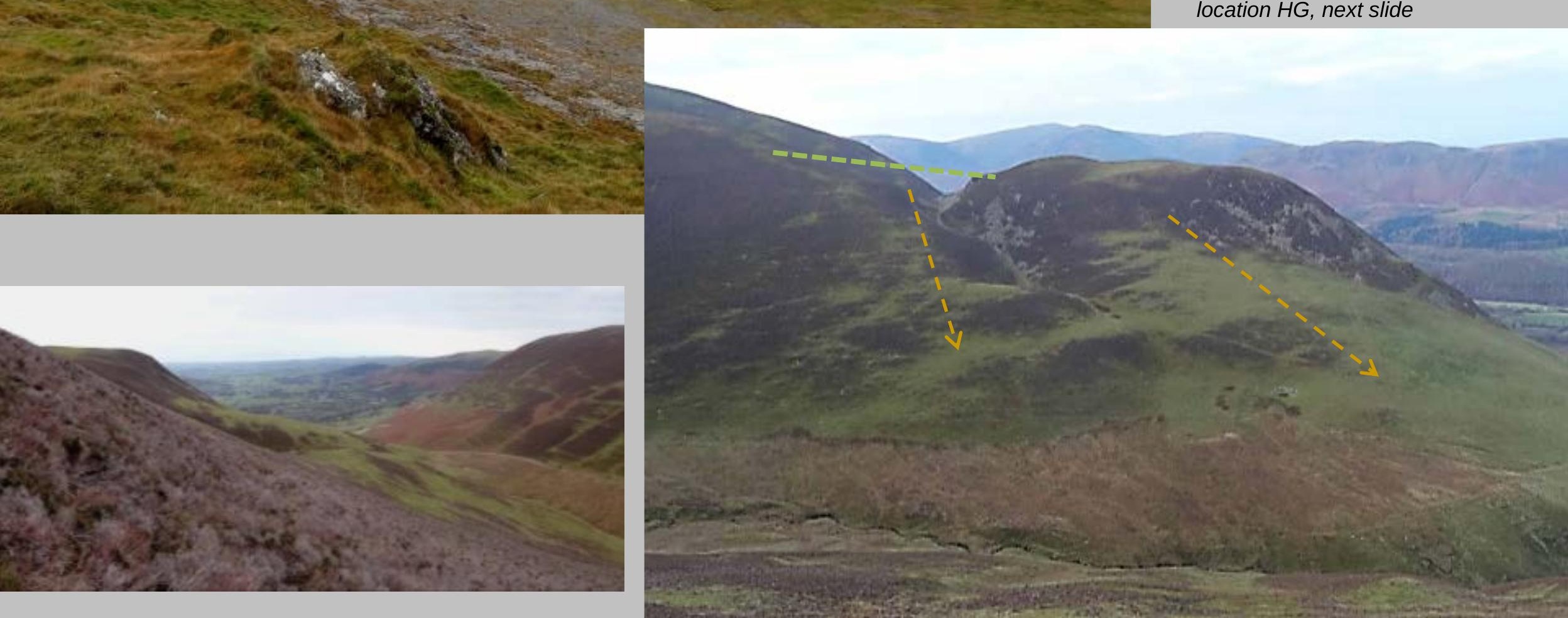


\section{SEEDI NG OF CI RQUES BY RSF CAVITIES}

This idea has a long pedigree (Clough 1897; Bailey \& Maufe 1916; Peacock et al. 1992; Evans 1997).

- Jarman (2003a) identified a dozen RSF cavities in SW Highlands as potential 'Clough proto-cirques' but as they face west or south are unlikely to develop into true cirques. Cavities of more promising aspect would already have been exploited as cirques, so that their RSF origins would now be less recognisable.

- Turnbull \& Davies (2006) and Evans (2013) debate extent to which cirques have developed from RSF cavities.

- Ballantyne (2013) illustrates gradation from extant and pre-LLS RSF cavities to more mature cirque forms.

A pre-LGM Dove Crags RSF would be a rare case of cirque seeding in the Lake District.

- most LLS glaciers of Sissons (1980) fully occupy cirques of conventional form, but in the NW Fells, Dove Crags (and Eel Crag / Hobcarton Crag - SI-35-36) show small glaciers within unusually large, angular cirques.

- cf. Whelter Crags, Haweswater (SI-41, cirque rim 720 m, floor 400 m OD; E aspect) - anomalously large cirque invading peripheral open upland, LLS glacier of contested extent (Sissons 1980; McDougall 2013), no trace of any RSF slipmass, floor conventionally stream-coursed; if of RSF origins, it would well predate the LGM.

The two Lake District 'cirqueforms' already reinterpreted as large RSF cavities may have good cirque seeding potential (I.S Evans, pers. comm., 2014) :

- Cotley (SI-41) - despite peripheral escarpment location, floor only 200-350 m OD, has good snowblow catchment, east-facing headscarp element could shield a small cirque glacier. But if RSF is pre-LGM, why so few signs of LGM cirque-glacier activity, indeed head scarp is degraded? [Dykes et al. (2010) do not discuss this].

- Clough Head (SI-40) - NW aspect - some snow-blow catchment - high floor 500 m OD (tho' convex form not ideally shaped for snow accumulation): "It should readily be glacially occupied and thus seed a true cirque". No evidence of LLS cirque occupancy, but headscarp and east couloir are subdued, not typical 'fresh' RSF; and deep sinuous features across Threlkeld Knotts 'slipmass' resemble glacifluvial channels.

[Davies et al. (2013) consider it postglacial; Dykes et al. (2010) do not consider its age].

In the Scottish Highlands, cirque-seeding is blurred by complete LGM / wide LLS ice cover :

- 'debris-free scarps' (Holmes 1984) imply post-LGM origins; most have forms / aspects unlikely to seed cirques.

- Sgùrr an Fhuarail is a possible pre-LGM RSF cavity evolving as a 'proto-cirque' - discussed in SI-49.

Assessing cirque morphologies for anomalies is likely to identify more candidates for pre-LGM RSF origins. 


\section{COP COMPARATOR SITES}

Clough Head RSF (Keswick-Penrith gap) $1.20 \mathrm{~km}^{2}$

see also SI-63

Threlkeld Knotts (below scar) are dislocated orthogonally slope on east is antiscarped deformation (remnant)

LiDAR image courtesy Tim Davies / Jeff Warburton, Univ Durham

view from Blencathra

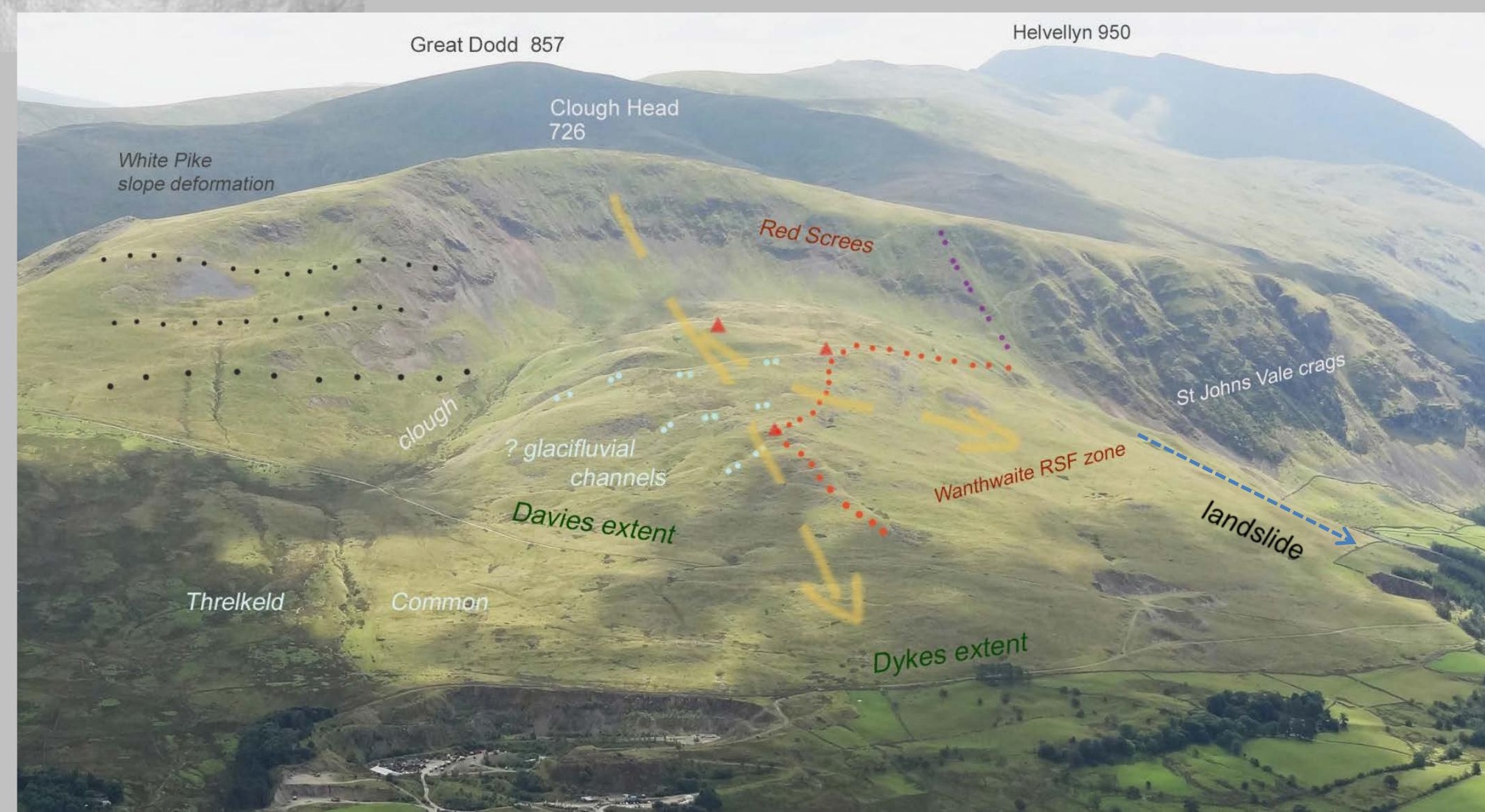




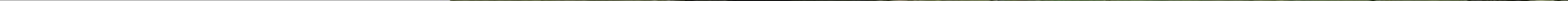




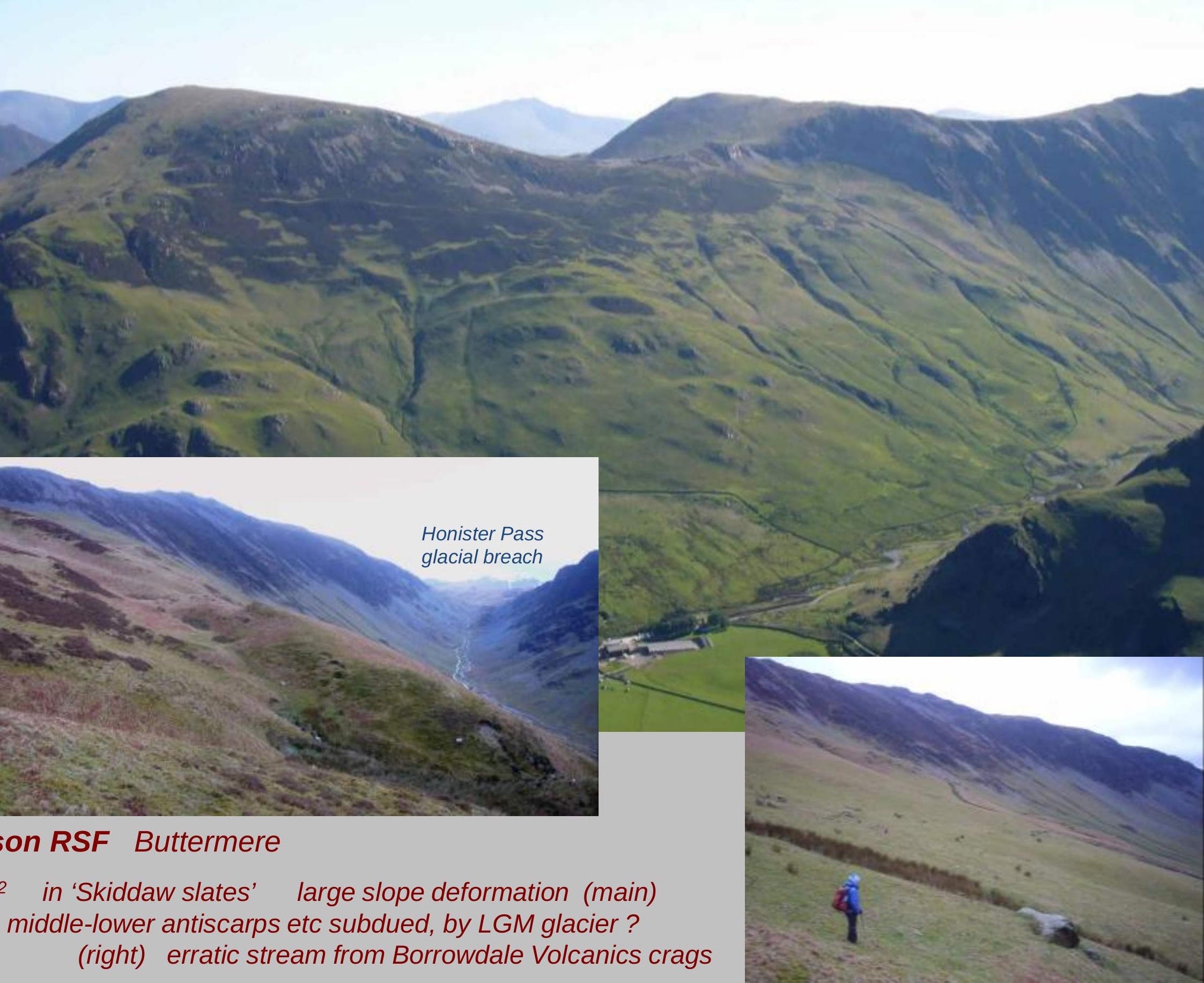




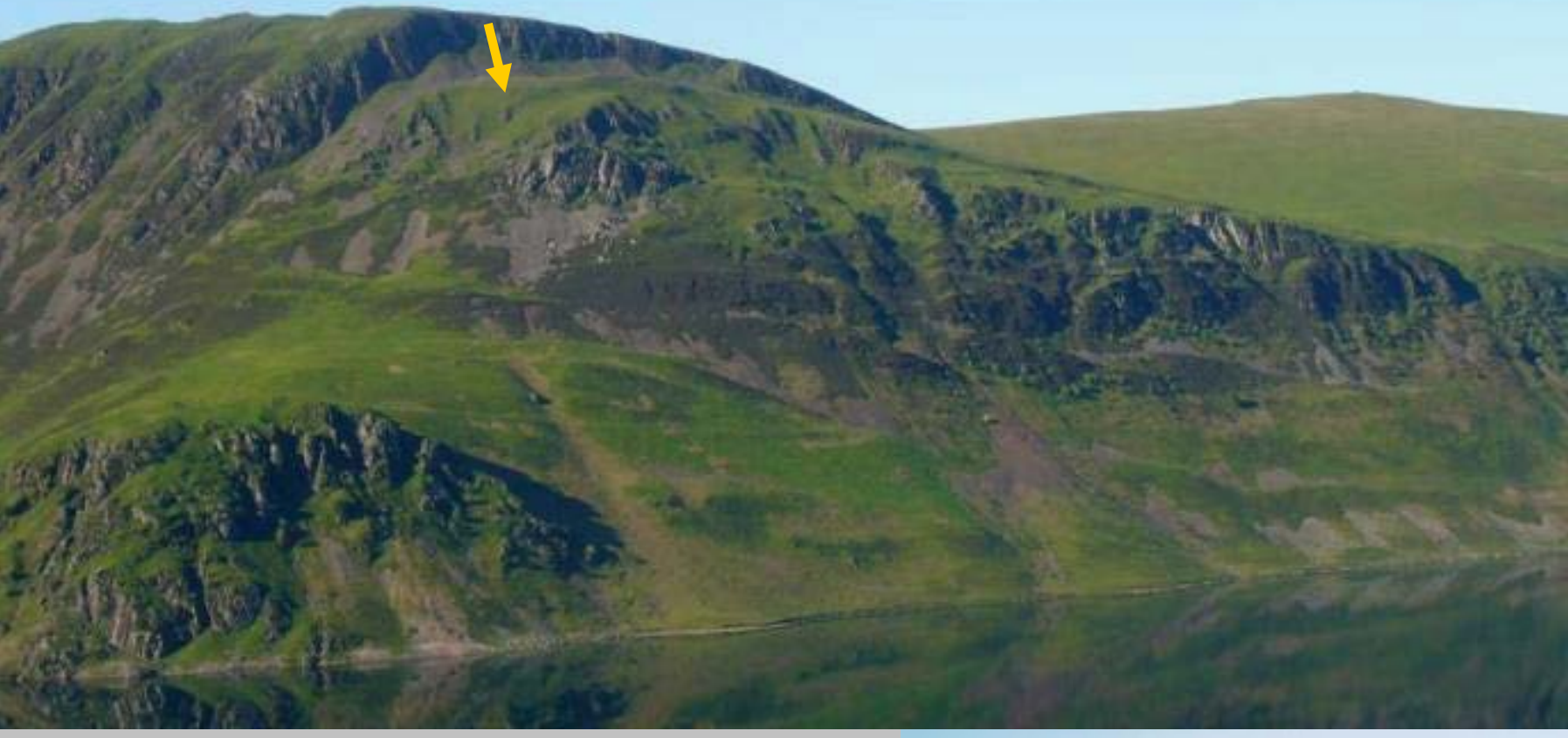

Fairfield RSF Helvellyn range

$0.30 \mathrm{~km}^{2}$ in Borrowdale Volcanics

\section{Revelin Crag RSF Ennerdale Water}

$0.55 \mathrm{~km}^{2}$

in 'Skiddaw slates'

slipmass lowered $\sim 30 \mathrm{~m}$
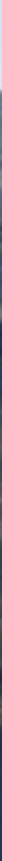


\section{Whelter Crags}

Haweswater

location - SI-02

peripheral outsize cirque at unusually low level, with fluvial neighbours

possible RSF origins in earlier cycles

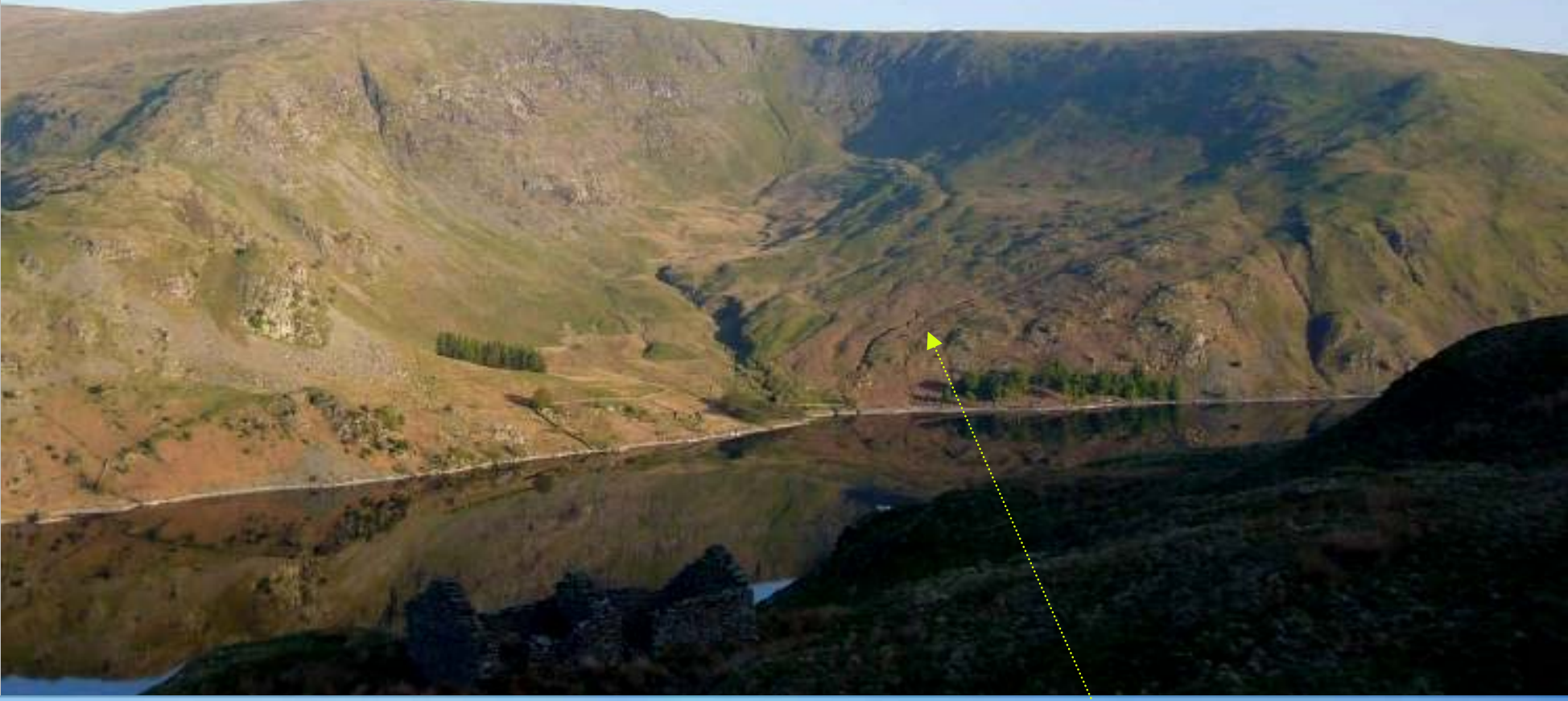

Harter Fell

High Street classic trough-head cirques of Mardale high fluvial valley

High Raise
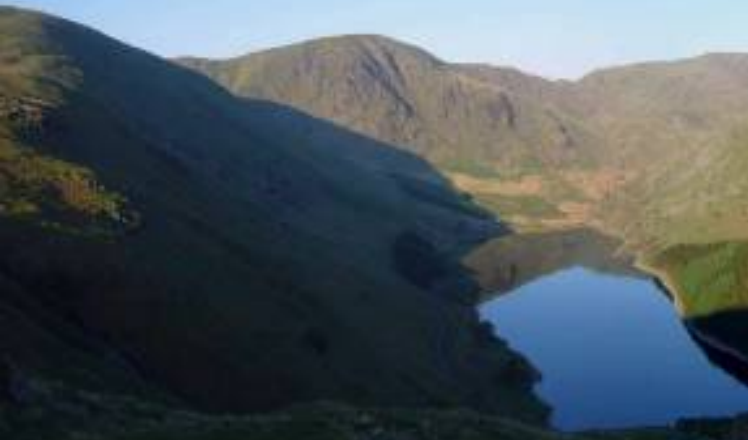

outsize cirque

slightly glaciated concavity 


\section{Pen yr Helgi-du RSF}

Cwm Eigiau, Carneddau, Snowdonia

$0.25 \mathrm{~km}^{2}$

- slipmass lowered by 120 m (arrowed)

- coherent former summit plateau surface

- no lateral restraint

- projects well out into trough, high rampart 


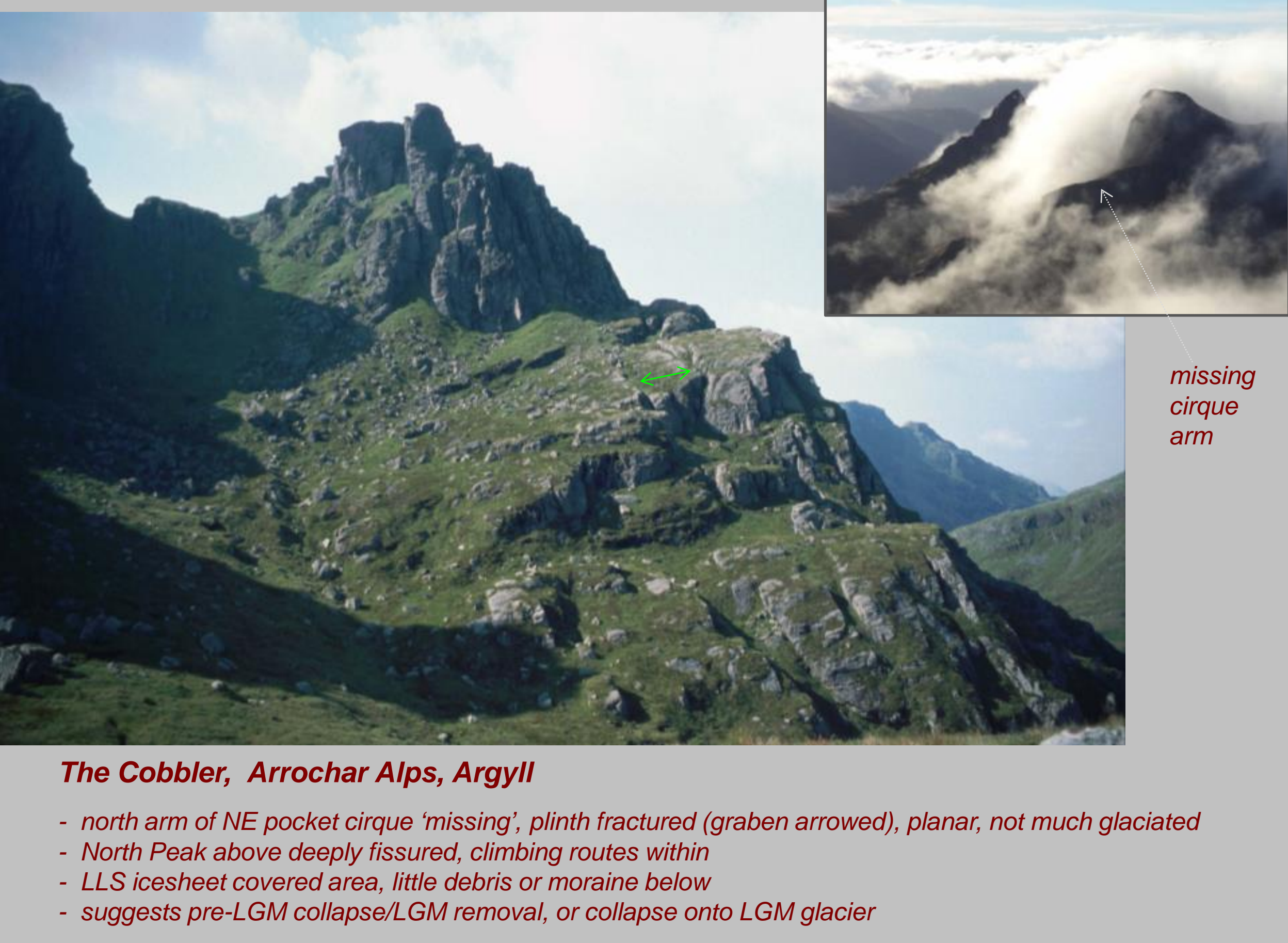




\section{Streap RSF}

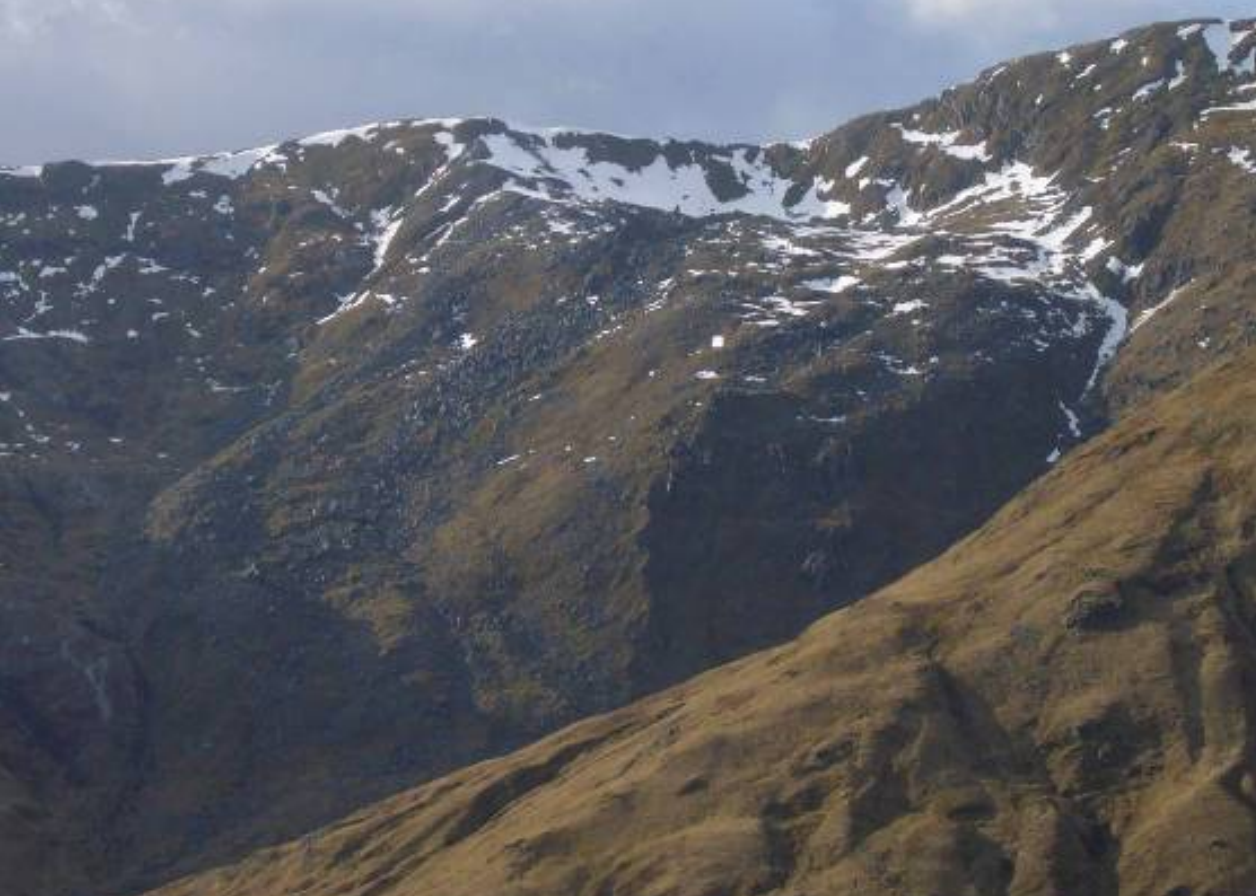

Glenfinnan

W Highlands $\quad 0.35 \mathrm{~km}^{2}$

- a 150 m-deep wedge cavity

- slipmass lowered by $100 \mathrm{~m}$

- much disrupted but still coherent former summit surface

- high toe rampart
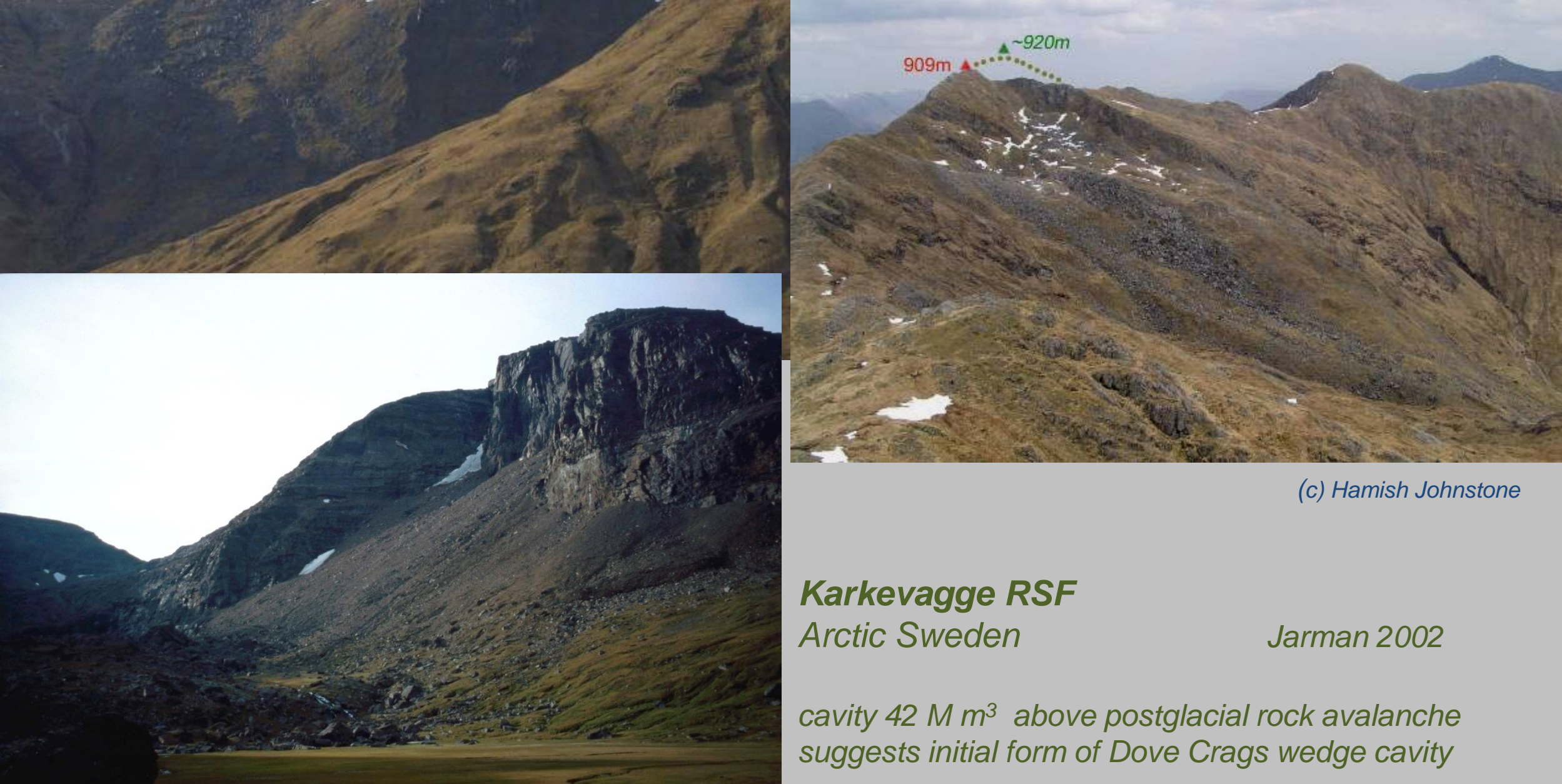

(c) Hamish Johnstone

Karkevagge RSF

Arctic Sweden

Jarman 2002

cavity $42 \mathrm{M} \mathrm{m}^{3}$ above postglacial rock avalanche suggests initial form of Dove Crags wedge cavity 


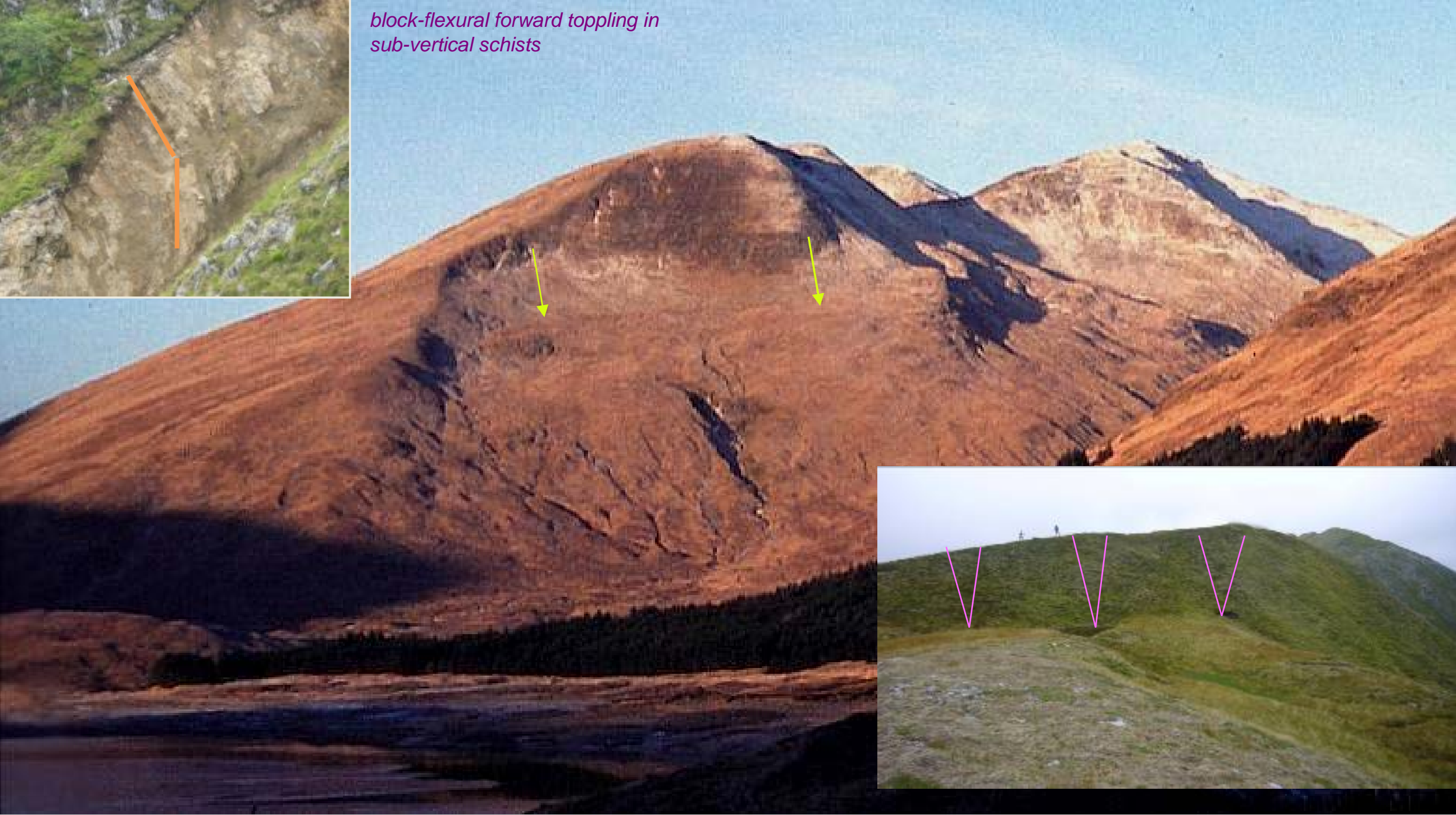

\section{Sgurr an Fhuarail (Cluanie-Glenshiel) - a classic 'proto-cirque'}

- the sloping planar floor may have been lowered (arrows) or be a stripped slice scar

- the gully incising its apron reveals failed, deeply-weathered bedrock (inset top L)

- the high headwall is unrelated, possibly shorn by an earlier RSF

- RSF splits the broad summit behind (13m scarp, inset - people for scale), and abounds up the side valley 


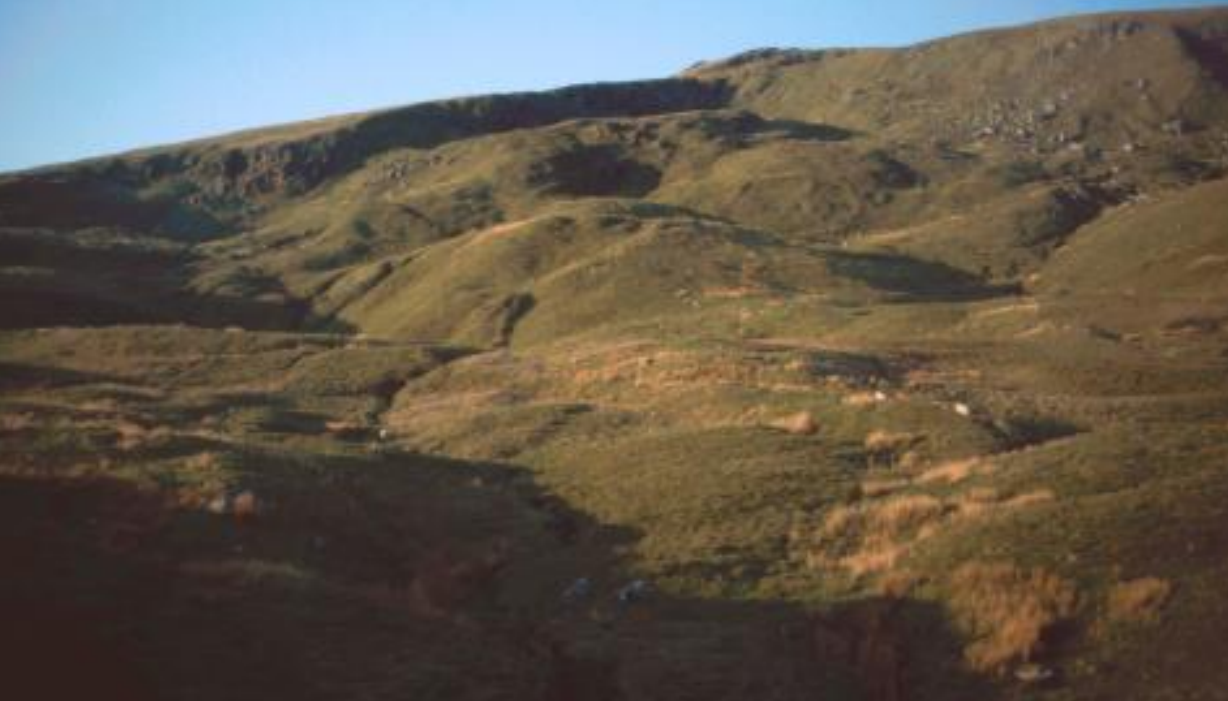

Tullich Hill RSFs, Luss Hills, S Highlands

multiple-wedge cavities on left apparently older cavity on right

- degraded headscarp

- underfit, pared- back slipmasses

- reactivated toe 


\section{is Dove Crags simply a pre-existing cirque, where the floor has failed?}

- the RSF here could simply be the cirque floor failing and its apron bulging outwards - since there is no longer any direct evidence for the 'cirque walls' being cavity scarps

- this is a variant on the 'rebound' model of RSF - where intense bedrock erosion creates unloading stresses causing the floor to rupture

- possible examples in the Highlands are

$>A^{\prime}$ Chioch (Affric) [NH113162] - RIGHT

$>$ Binnein an Fhidhleir (Argyll) [NN 229 103] - BELOW

- however both are probably slipmasses which have reactivated after long descent and complete paring back by valley glaciers

- at Dove Crags, the volume and cavity-match of the extant bulge is the best argument against this 'rebound' interpretation

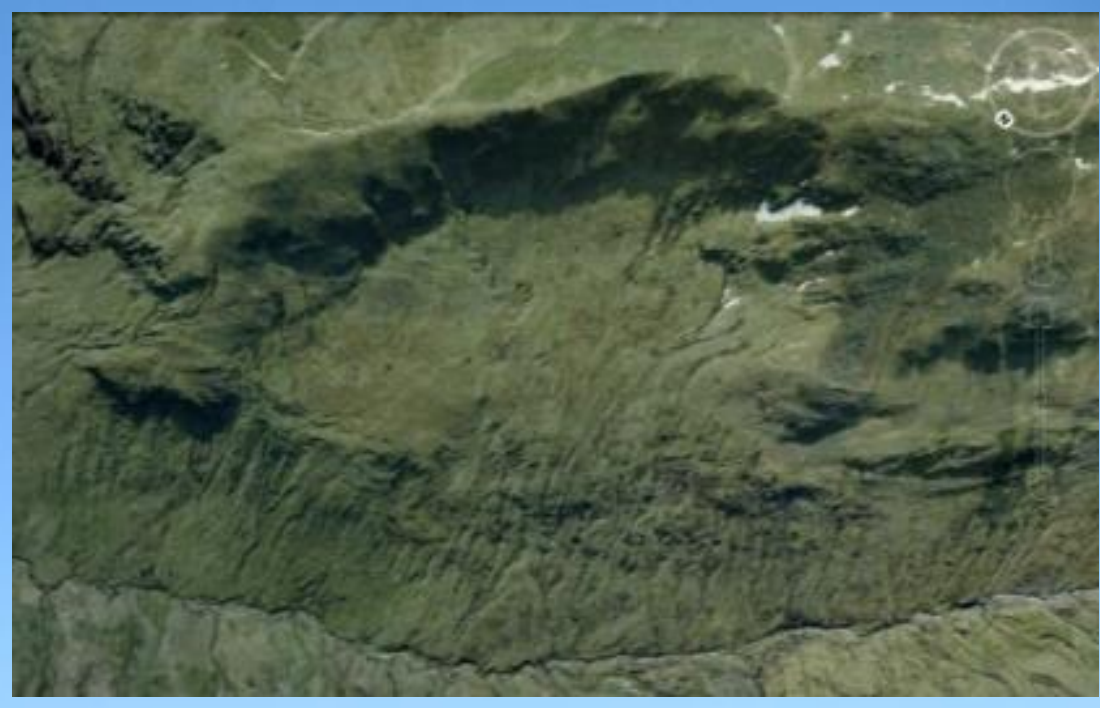

A'Chioch - floor split by step-scarp, left half smooth, ungullied, fractured, antiscarps along projecting lip;

- faces $N$ so is developing as cirque

Fhidleir - slippage from 'bathtub ring' scarp at foot of headwall - antiscarps, but surface streams indicate consolidation - faces S so limited scope to develop as cirque

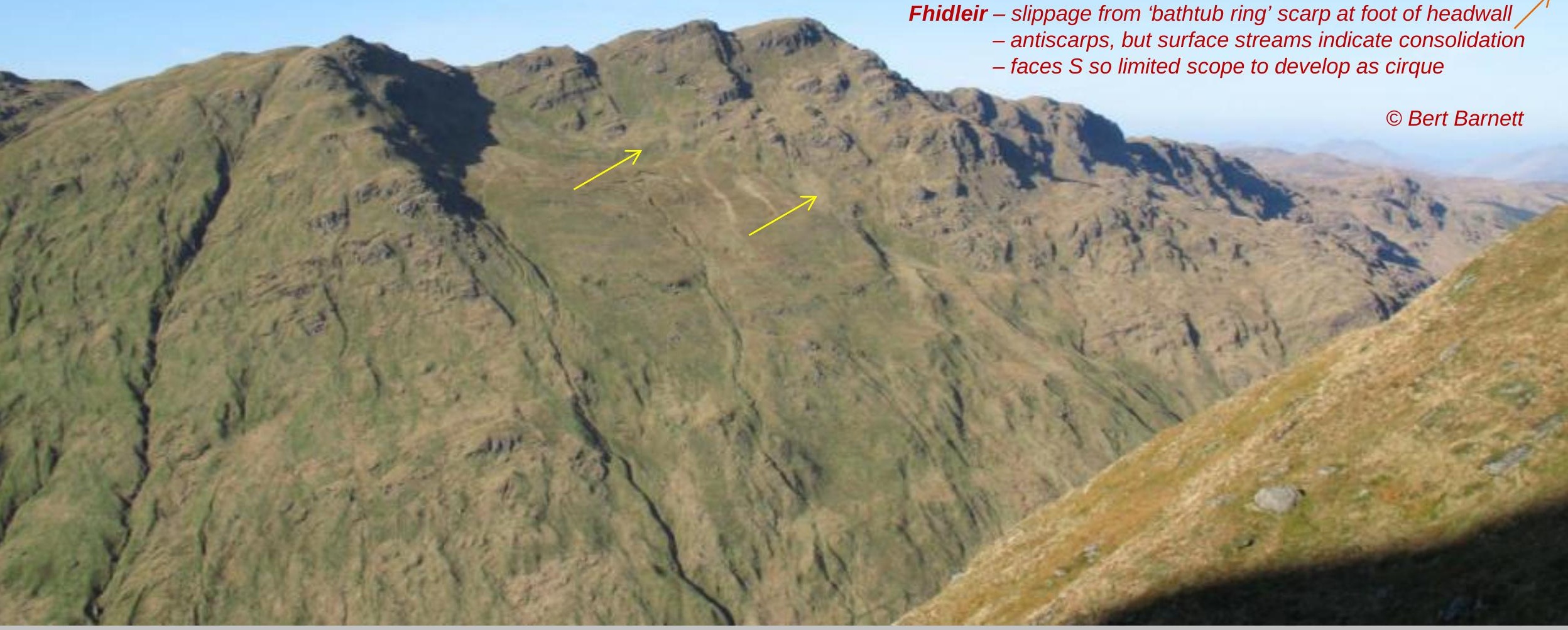




\section{is Dove Crags a parafluvial RSF? as the V-form of Gasgale Gill might suggest}

A small proportion of British upland RSFs occur in partly or wholly fluvial valley contexts and, where not directly attributable to fluvial undercutting, may be termed 'parafluvial' RSFs (sensu Jarman 2011; Jarman et al. 2014). While most Lake District RSFs are paraglacial (sensu Ballantyne 2002), nine are fluvial, such as those on Latrigg undercut by the (?glacifluvial) incision of the Greta gorge (Wilson \& Smith 2006; Dykes et al. 2010), or parafluvial, notably a group north of Skiddaw.

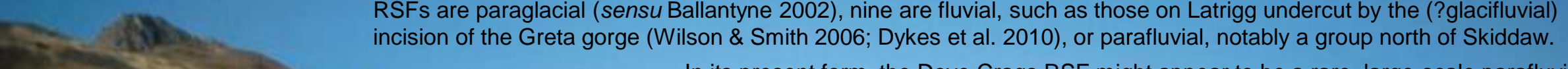

In its present form, the Dove Crags RSF might appear to be a rare, large-scale parafluvial RSF in a deep V-shaped valley (Fig. 8). However, if as argued, Gasgale Gill had a U-shaped glacial profile earlier in the Pleistocene, then it is the large slipmass bulge which has created the asymmetric $V$-profile of non-fluvial origin (excluding the basal cutbank).

Dove Crags RSF is therefore proposed as being essentially paraglacial.

\section{Beinn Buidhe parafluvial RSF, Arnisdale, W Highlands}

preglacial fluvial upper valley (interlocking spurs) incising down to glacial trough, glacifluvial inburst on $R$ 
1- cavities occupied by dead ice

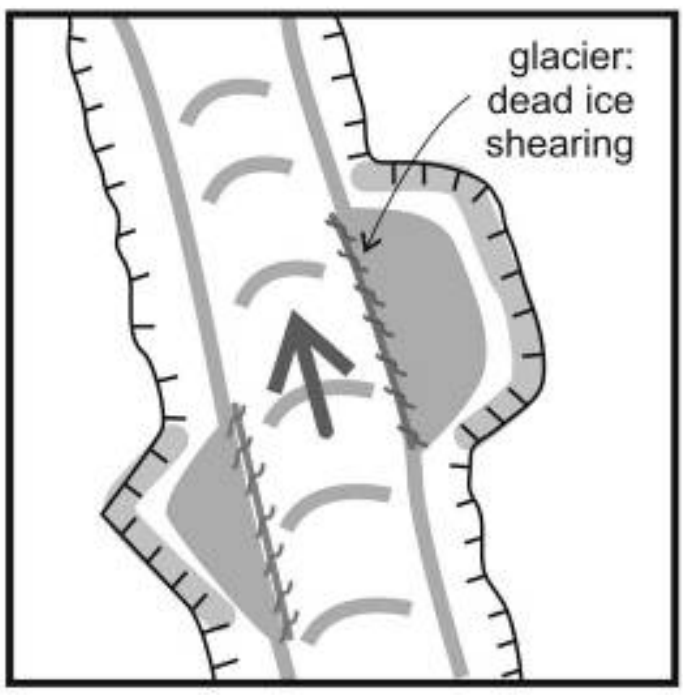

3- nose between cavities promotes trough deepening

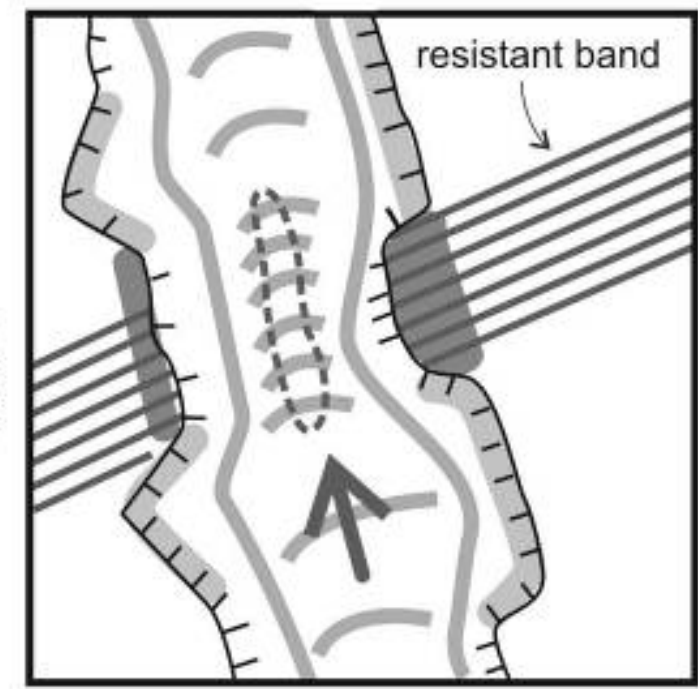

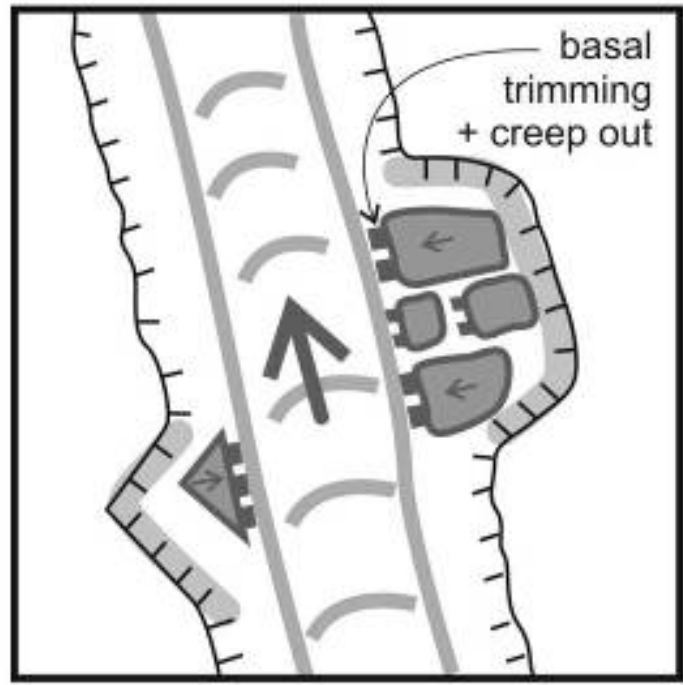

2- cavities

occupied

by failed

masses

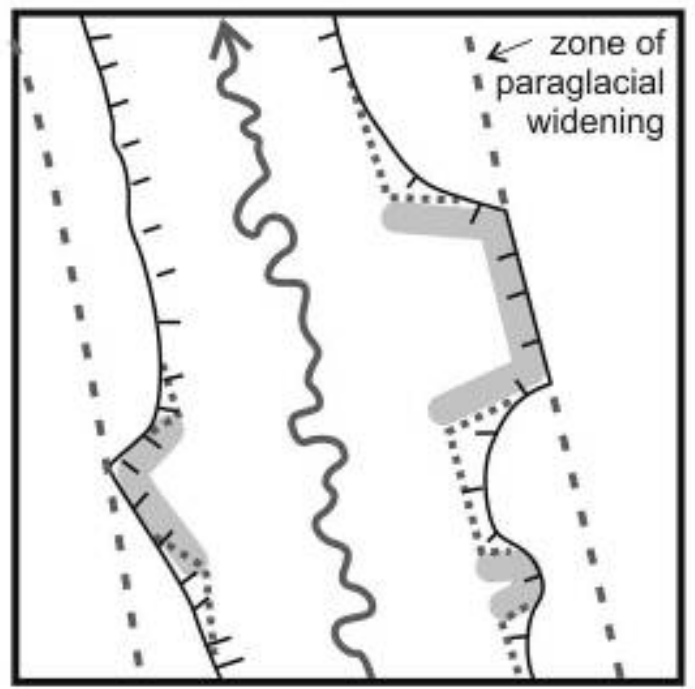

4- only angles of cavities shaved off 


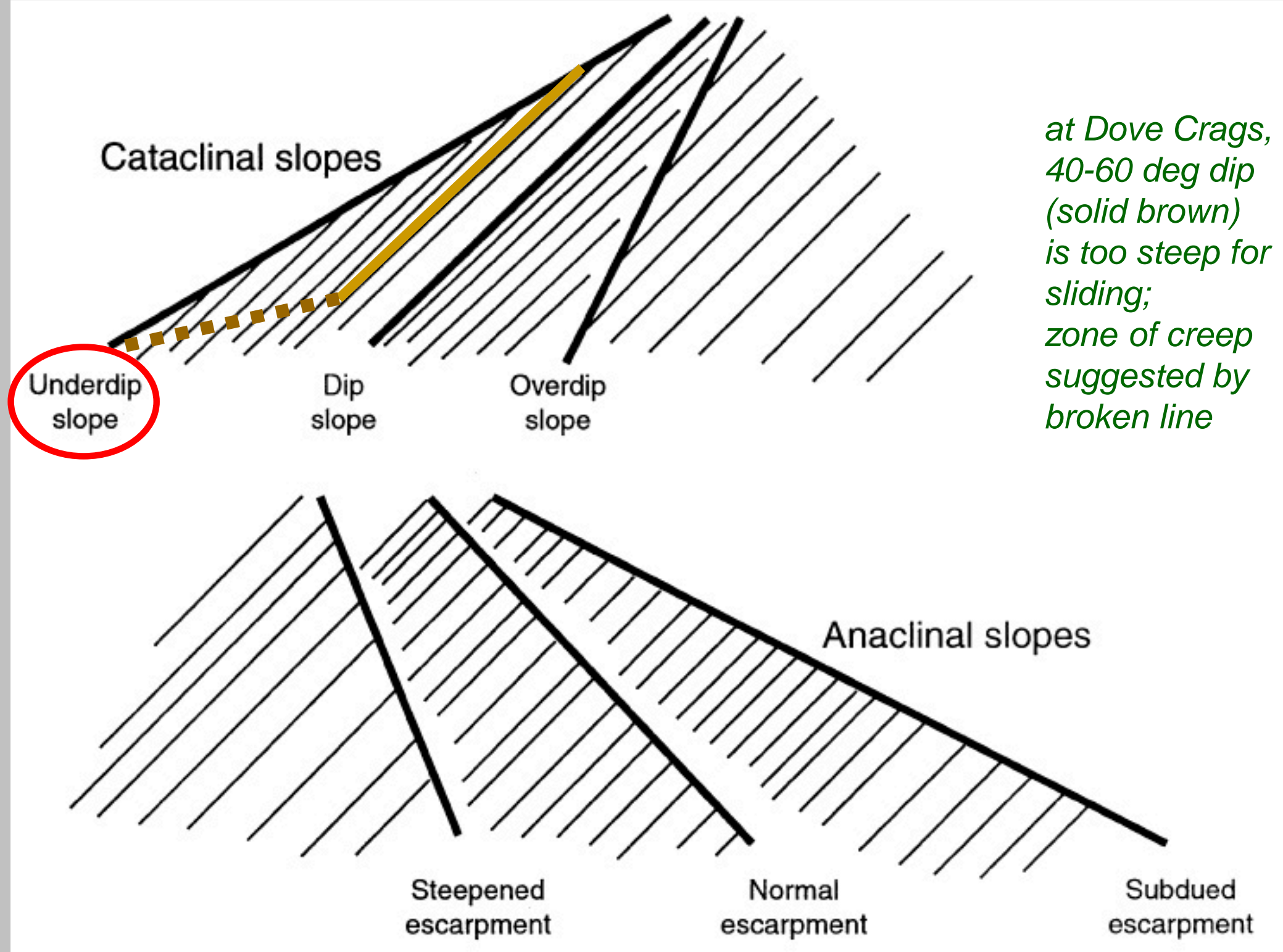

slope classification schema from Cruden 2000 (Fig. 1)

structural controls on RSF form and movement 


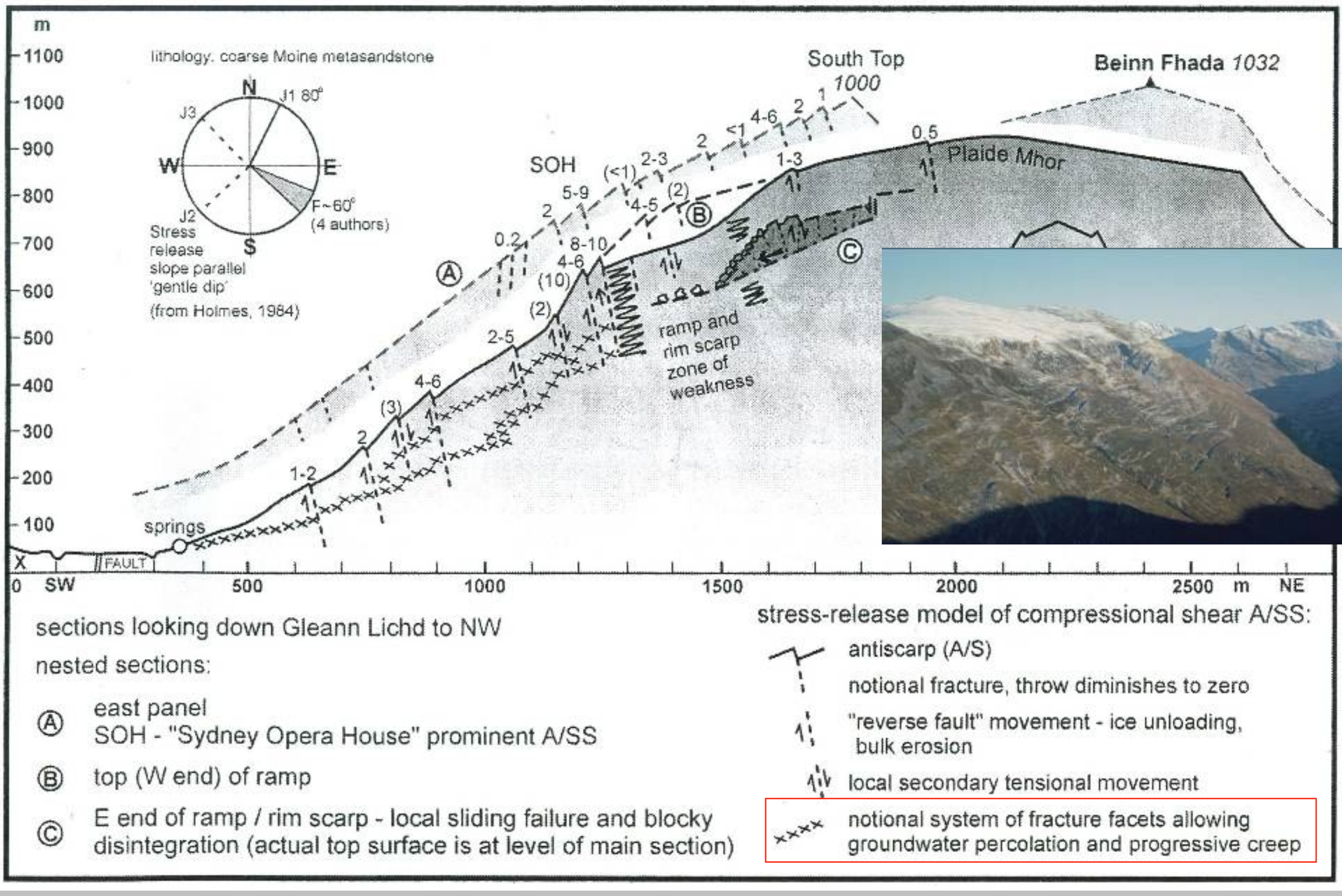

\section{Beinn Fhada RSF, W Highlands}

from Jarman (2006)

in absence of suitably inclined sliding planes, creep along a 'zone of crush' or fracture facets is inferred 


\section{axiomatic : $\quad$ RSF visible cavity and visible slipmass must be 'in balance'}
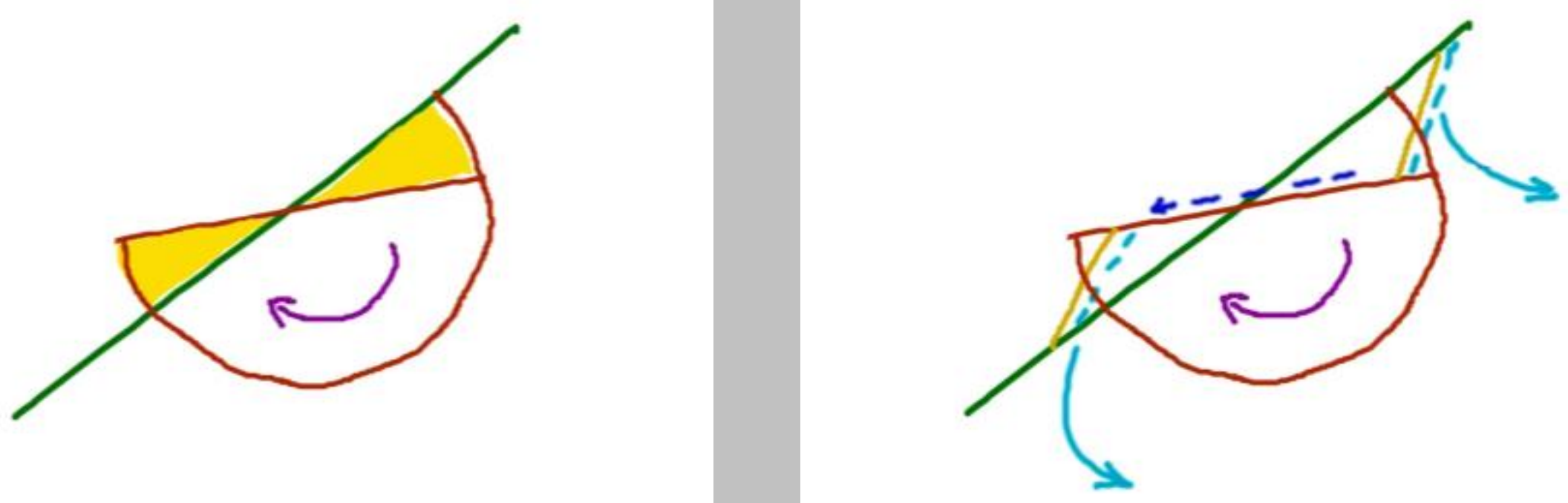

- pivoted failure

- no downslope movement

- large 'hidden iceberg'

(sector 2 in next slide)
- degradation of headwall and toe remain in balance (on-site)

- LLS cirque erosion and moraines remain in balance

- LGM cirque erosion and paring of toe alter balance if exported from system 


\section{Grasmoor}

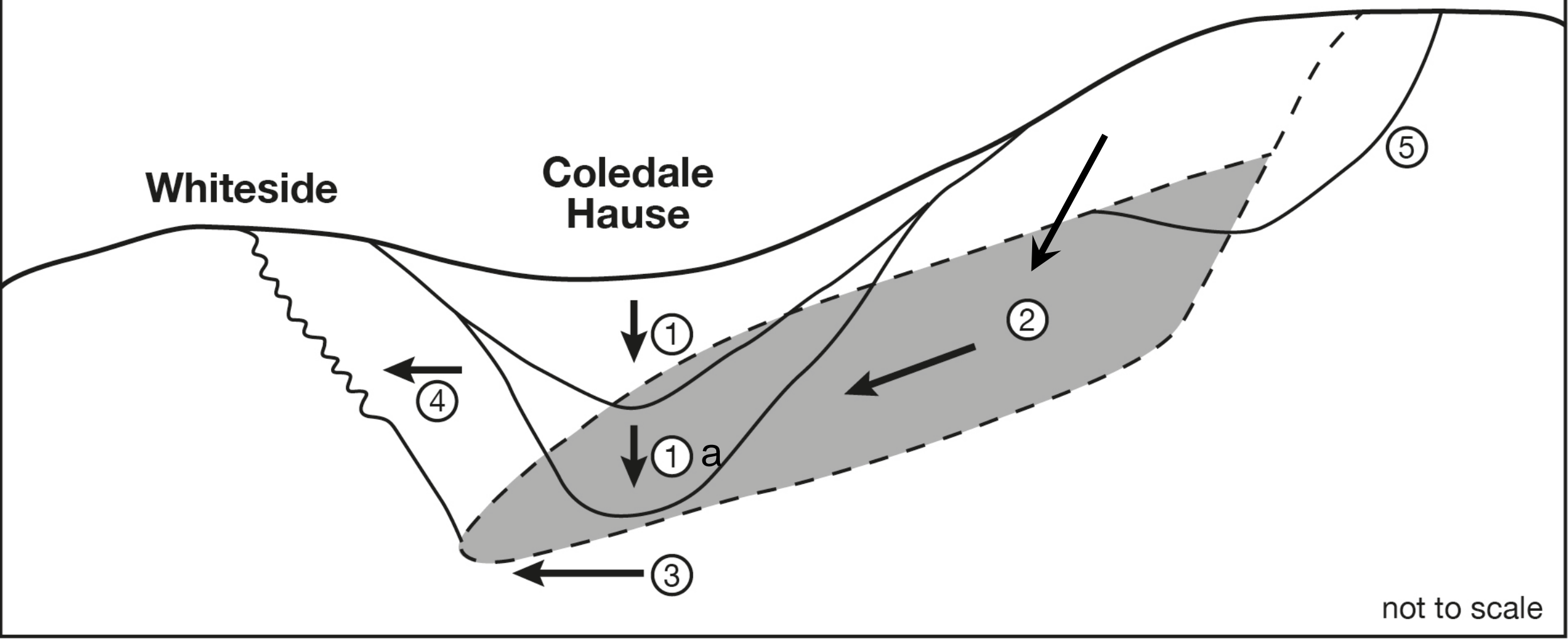

interaction of events - no timescale (proposed timescale - next slide)

1. Iong-term fluvial incision of Gasgale Gill into rolling paleic (pre-Quaternary) upland surface

1a. periodic enlargement by relatively modest valley glacier

2. mass movement (hybrid creeping translational slide RSF) from Grasmoor into valley

3. valley axis displaced north

4. Liza Beck undercuts Whiteside, valley wall steepens and retreats, sharpening crest to half-arête.

5. mass movement cavity partially modified into glacial cirque, invading Grasmoor plateau. 
